\title{
EL ENVEJECIMIENTO DE LA POBLACIÓN Y SUS REPERCUSIONES EN EL ESPACIO URBANO DE LA CIUDAD DE ZARAGOZA
}

\author{
Aging process in the city of Zaragoza and its impact \\ on the urban space
}

\author{
Enrique Alegre Vicente ${ }^{1}$
}

Recibido: 15/10/2012 Aceptado: 18/01/2013

Resumen. El proceso de envejecimiento es un hecho constatable en el espacio urbano de Zaragoza, aunque el grado de afección del fenómeno es diferente en uno u otro de los distritos que lo componen. Así en un marco geográfico como el propuesto, cada una de sus unidades administrativas o censales ofrece un patrón determinado, que se refleja en su estructura demográfica, y conforma su espacio urbano de una forma diferente. El análisis diferenciado de este hecho es el objeto de este trabajo, en un ejercicio que pretende estudiar las múltiples parcelas en las que se manifiesta el proceso de envejecimiento, desde el puramente demográfico hasta su repercusión en las características de los hogares o en los diferentes servicios y el equipamiento urbano. En definitiva nuestro estudio ofrece un análisis del envejecimiento demográfico de la ciudad de Zaragoza, del grado de afección en sus diferentes distritos y de la relación de este proceso con el espacio en donde se desarrolla. Un fenómeno generalizado en las sociedades industriales pero que reviste caracteristicas particulares en función del espacio de estudio.

Palabras clave: Zaragoza, población, envejecimiento, equipamiento, urbano.

Abstract. The aging process is a verifiable fact in the urban space of Zaragoza, but the degree of disorder of the phenomenon is different in either of its districts that comprise it. So in a analysis as proposed, each of its administrative or census units provides a model that is reflected in its demographic structure, and forms its urban space in different ways. The separate analysis of this is the subject of this work, in an exercise that aims to study the multiple areas where aging process is manifested, from the purely demographic way to its impact on household characteristics or different services and urban facilities. Definitively our study provides an analysis of the aging process in the population of the city of Zaragoza, the degree of involvement in the different districts and the relation of this process with the space in which it develops. Widespread in industrial societies but which has unique characteristics in terms of studio space.

Key words: Zaragoza, population, aging, equipment, urban.

\section{INTRODUCCIÓN}

Zaragoza, vista desde el contexto regional europeo es un punto neurálgico en el sudeste del continente, centro de un polígono cuyos vértices estarían formados por Madrid,
Valencia, Barcelona, Toulouse, Burdeos y Bilbao, "emplazada en el centro de un área que, en un radio de 350 kilómetros, reúne el $60 \%$ de la población española y el $80 \%$ de su PIB" ${ }^{2}$. Tradicional centro regional de desarrollo económico es, a partir de los años 60 del siglo pasado, cuando

(') enriquealegre@terra.es. Licenciado en Geografia. Alumno del Master "Técnicas Avanzadas de Investigación Histórica, Artística y Geográfica". (2) PLUMED GÓMEZ, A.: Zaragoza horizonte 2008: hacia la consolidación de proyectos urbanísticos a gran escala y propuesta de conectividad en transporte público. Barcelona, Universitat Politècnica de Catalunya, 2009, p. 4. 


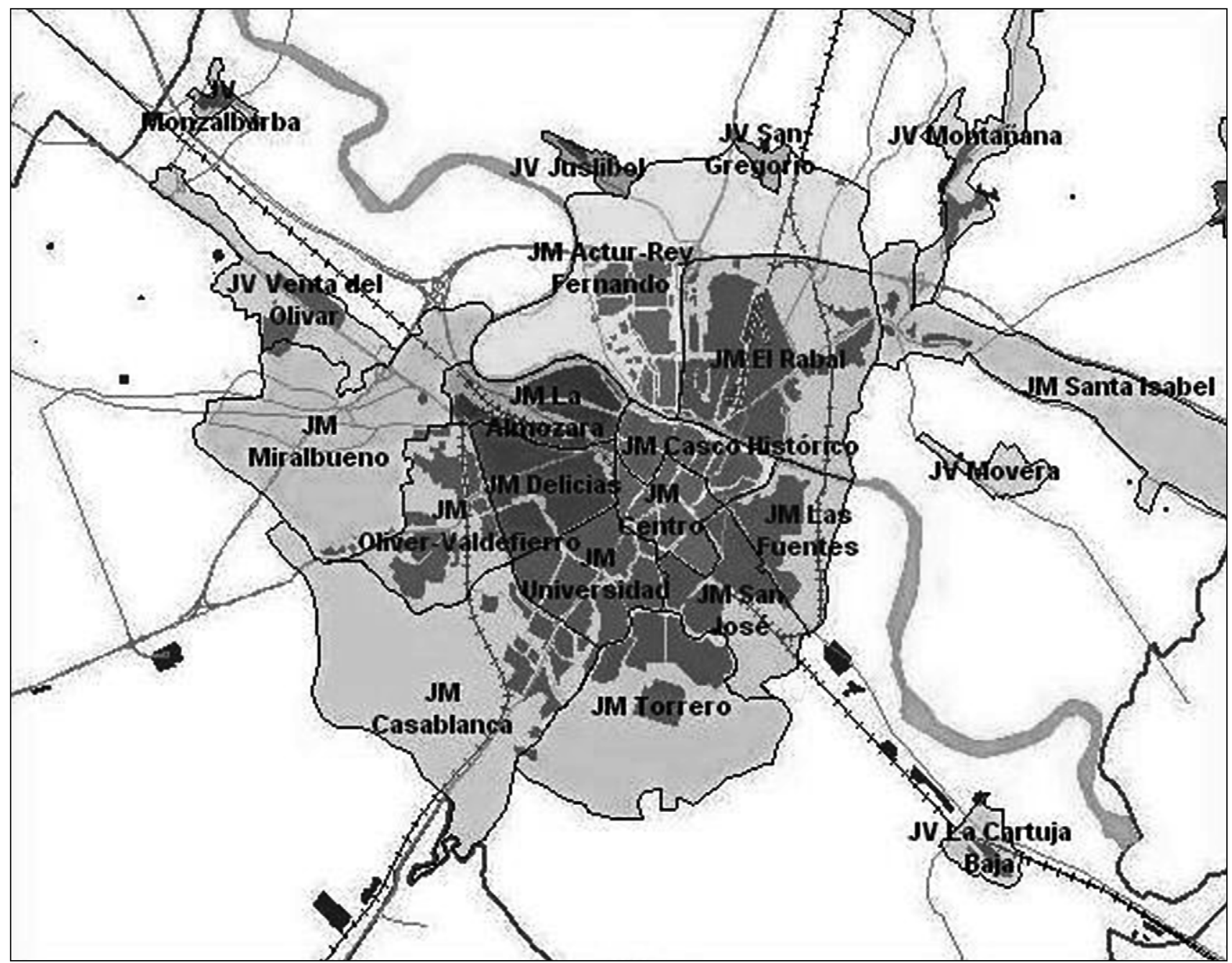

A Figura 1. Distribución de las Juntas Municipales y Vecinales. Fuente: Ayuntamiento de Zaragoza.

queda definido, a grandes rasgos, su desarrollo urbanístico actual y acaba por configurarse como un islote industrial que añade un nuevo factor al ya preexistente desequilibrio interregional. En los años sucesivos se agudizará el proceso de concentración hasta exagerar la macrocefalia de Zaragoza tanto en su estructura socioeconómica, con una fuerte concentración industrial, como en su potencia demográfica, en un territorio semivacio con muy bajas densidades de población; los datos del IAEST ${ }^{3}$ arrojan una evolución para la capital desde los $566 \mathrm{~h} / \mathrm{km}^{2}$ (1996) a 692,9 h/km² (2011), (56,3 hab $/ \mathrm{km}^{2}$ es la densidad provincial en este último año); en torno a los $9 \mathrm{~h} / \mathrm{km}^{2}$ para la provincia de Teruel, sin apenas variación en la serie estudiada, o los $14 \mathrm{~h} / \mathrm{km}^{2}$ para la de Huesca, casi sin incremento desde los 12,46 h/km² de 1991.

La ciudad aglutina más de la mitad de los habitantes de la comunidad, 698.186 según datos el padrón de 2011, en un término municipal de gran extensión, $1.060 \mathrm{~km}^{2}$ que engloba 14 distritos urbanos y un distrito rural, compuesto a su vez por 14 barrios rurales, núcleos y entidades singulares; no obstante el grueso de la población se localiza en el casco urbano propiamente dicho, descendiendo su magnitud hacia la periferia. Si desde los años 60 la inmigración rural ha sido continua, en un acelerado proceso de urbanización, a partir de los años 90 se observa un fuerte incremento de la población extranjera, pasando a contar en 2011, según datos del padrón, con 108.234 residentes. En este sentido la estructura de Zaragoza es compleja, ya que el 96\% de la población se concentra en menos del $25 \%$ de su superficie, lo que se traduce en un centro denso y una periferia poco poblada; un reparto desproporcionado entre barrios rurales (4,4\% de la población, 31.124 habitantes) y casco urbano $\left(95,6 \%, 667.062\right.$ habitantes) ${ }^{4}$.

(3) INSTITUTO ARAGONÉS DE ESTADÍSTICA. Datos referenciados al periodo 1996-2011.

http://servicios3.aragon.es/analytics/saw.dll?Go\&path=/shared/IAEST-PUBLICA/MENUWEB/Territorio/Densidad/020001TM\&Action=Navigat e\&NQUser=granpublico\&NOPassword=granpublico\&Options=df

(4) Datos del padrón municipal de Zaragoza, 2011. Unidad de Estadistica y Gestión Padronal, Ayuntamiento de Zaragoza. 
Su organización administrativa la componen 15 distritos, divisiones territoriales con órganos de gestión propios (mapa 1), cuyos centros de gobierno radican en 14 Juntas Municipales para los distritos urbanos, completadas con un distrito rural que comprende, a su vez, otras 14 entidades menores, barrios rurales, dirigidos desde las Juntas Vecinales.

Los distritos urbanos son los siguientes:

Centro, Casco Histórico, Delicias, Universidad, San José, Las Fuentes, Almozara, Oliver-Valdefierro, Torrero, Actur-Rey Fernando, El Rabal, Casablanca, Santa Isabel, Miralbueno.

Existe un último distrito, el Distrito Rural, que comprende Las Juntas Vecinales o barrios rurales de Alfocea, Casetas, Garrapinillos, Juslibol-El Zorongo, La Cartuja Baja, Montañana, Monzalbarba, Movera, Peñaflor, San Gregorio, San Juan de Mozarrifar, Torrecilla, Venta del Olivar y Villarrapa" ${ }^{5}$. Las fuentes municipales agrupan estos en Barrios Rurales Norte y Barrios Rurales Oeste.

Otro ámbito de análisis es el de distrito censal, que se refiere exclusivamente a términos estadísticos y es utilizado por los organismos competentes (IAEST, INE); en el caso de Zaragoza, como veremos más adelante, el IAEST, divide la ciudad en 12 distritos censales. En este trabajo recurriremos a él cuando las fuentes municipales no nos ofrezcan suficiente información.

\subsection{Algunos apuntes metodológicos}

En la elaboración de este trabajo debemos de señalar varios obstáculos que han condicionado la fase de análisis; el más importante, y que influye en la forma de acometer el estudio, radica en la diferente presentación de los datos por parte de la Unidad de Estadística y Gestión Padronal del Ayuntamiento de Zaragoza y el IAEST ${ }^{6}$. En el primer caso, la explotación del padrón de 2011 se realiza desglosado por distritos administrativos (Juntas Municipales y Juntas Vecinales), en número de 15 (14 urbanos y uno rural). En el caso del IAEST la información demográfica se nos ofrece en 12 distritos censales (10 urbanos y 2 rurales), por ello hemos aplicado una solución ecléctica a la hora de presentar los resultados; así analizaremos los datos demográficos de los distritos urbanos con la información procedente del Ayuntamiento de Zaragoza, por representar el volumen más exhaustivo y, por ende, que da mayor fiabilidad al análisis, pero agruparemos las juntas vecinales de los barrios rurales (14 para la administración municipal) en los dos distritos cen- sales, correspondientes a los Barrios Rurales Norte y Barrios Rurales Oeste, que presenta el IAEST al no existir información municipal para los aspectos socioeconómicos.

De otro lado, el segundo inconveniente radica en la falta de publicación del Censo de Población y Vivienda de 2011 en las fechas de realización del presente estudio. A causa de ello hemos debido de tomar como referencia más reciente el que corresponde a 2001, solamente accesible a través del IAEST, con la reducción comparativa de distritos respecto a los del ayuntamiento antes referida, por lo que, necesariamente, este artículo ofrece sus conclusiones en base a la extrapolación de los datos de ambas fuentes.

\section{DISTRITOS MUNICIPALES Y ESTRUCTURA DEMOGRÁFICA}

La especial incidencia del envejecimiento en el medio urbano es un hecho constatado, buena parte de los ancianos españoles vive en las grandes ciudades; según el Censo de Población y Viviendas de $2001^{7}$, seis de cada diez españoles de 65 y más años de edad residen en ciudades de más de 20.000 habitantes y cuatro de cada diez en núcleos de más de 100.000 habitantes. Los indicadores demográficos señalan que Aragón tiene un $20 \%{ }^{8}$ de población mayor de 65 años, frente al 17,2\% de España, (se han incrementado un $0,2 \%$ y un $0,3 \%$ respectivamente desde 2008). Por su parte Zaragoza ofrece magnitudes del 18,4\%, la misma que las de población joven de 0 a 19 años; esta desafortunada proporción no se cumple en las otras dos capitales aragonesas, asi en Huesca el peso de los jóvenes es del 20,1\% frente al 17,6\% de los mayores; Teruel presenta una relación todavía más favorable en términos comparativos, un 20,9\% de jóvenes frente a un $17,7 \%$ de los grupos de población superiores.

\subsection{Un análisis de los contingentes de población por distritos}

A la luz de lo que las fuentes arrojan, y atendiendo a su nivel de envejecimiento, podemos dividir el conjunto en 3 grupos de distritos:

1. Zonas con más de un $20 \%$ de población envejecida. Todos se sitúan en la margen derecha del Ebro, suelen ser los más antiguos, con poco espacio disponible para crecer y han sufrido la salida de parte de su

(5) AYUNTAMIENTO DE ZARAGOZA Y ZARAGOZA GLOBAL: Atlas de la ciudad. Zaragoza 2009. Zaragoza, Ayuntamiento de Zaragoza y Zaragoza Global, 2009, p. 20.

http://www.zaragoza.es/contenidos/Atlas_Zaragoza_2009/Atlas_A.pdf

(6) INSTITUTO ARAGONÉS DE ESTADISTICA.

(7) INE. Censo de Población y Viviendas 2001

(8) IAEST. Indicadores de estructura demográfica, 2011. 
población joven hacia otras localizaciones de mayor crecimiento urbano y mejores servicios. En general han sido tradicionales receptores de población inmigrante, de la que todavía presentan altos porcentajes. En este grupo incluiremos Centro, Casco Histórico, Delicias, La Almozara, Las Fuentes, San José, y Universidad.

2. Distritos con porcentajes medios de envejecimiento, de entre el $16 \%$ y el $20 \%$. Corresponden a los que, por su posición extrema al casco urbano, se han comportado demográficamente como núcleos rurales, son los situados en los límites del término municipal, Barrios Rurales Norte y Oeste, o los que, localizados en el casco urbano, han recibido grandes aportes de población extrajera, atenuando el proceso de envejecimiento, como Torrero-La Paz. En todos los casos su tendencia camina hacia un agravamiento de la situación demográfica, en un proceso lento pero continuo de incremento de las cohortes más altas de población.

3. En este grupo incluiríamos aquellas zonas con menos del 16\% de mayores de 65 años. Son distritos situados en el anillo exterior del casco urbano y cuyos límites están marcados por los distritos rurales. Se incluyen aquí todos los de la margen izquierda del Ebro, que han sido el soporte de la ex- pansión urbana iniciada a mediados de los años 90, concentrando población joven, lo que ha provocado el vaciado de los distritos del grupo 1; se incluyen en éste los de Casablanca, Actur, El Rabal, Miralbueno, Oliver y Santa Isabel.

\subsubsection{Grupo 1. Distritos de posición central, tasas altas de envejecimiento}

Aqui el grado de envejecimiento es muy alto, supera el $20 \%$, con tasas que, como en el caso de Centro se elevan hasta el 25,13\%, y con una gran desproporción en relación a los menores de 15 años, 10,95\%. En los últimos años, y en la mayoría de los casos, han visto reducido su peso específico dentro del conjunto urbano. Una característica distintiva es el alto nivel de población sobreenvejecida, mayores de 80 años, que ronda el 5\%. Incluimos en el grupo los distritos Centro, Casco Histórico, Delicias, La Almozara, Las Fuentes, San José, y Universidad; entre ellos, casos paradigmáticos son los de Centro y Casco Antiguo.

Al distrito Centro le corresponde la superficie más pequeña $\left(1,8 \mathrm{~km}^{2}\right)$ por lo que, teniendo en cuenta su elevada población, 58.301 habitantes, suma una alta densidad $\left(3.042,4 \mathrm{~h} / \mathrm{km}^{2}\right)$. Respecto a los datos del padrón de 2008, 56.975 habitantes, ha visto disminuido su potencial demográfico en un 4,03\%. Este fenómeno viene produciéndose desde antiguo así, tal y como señalan los datos del IAEST ${ }^{9}$

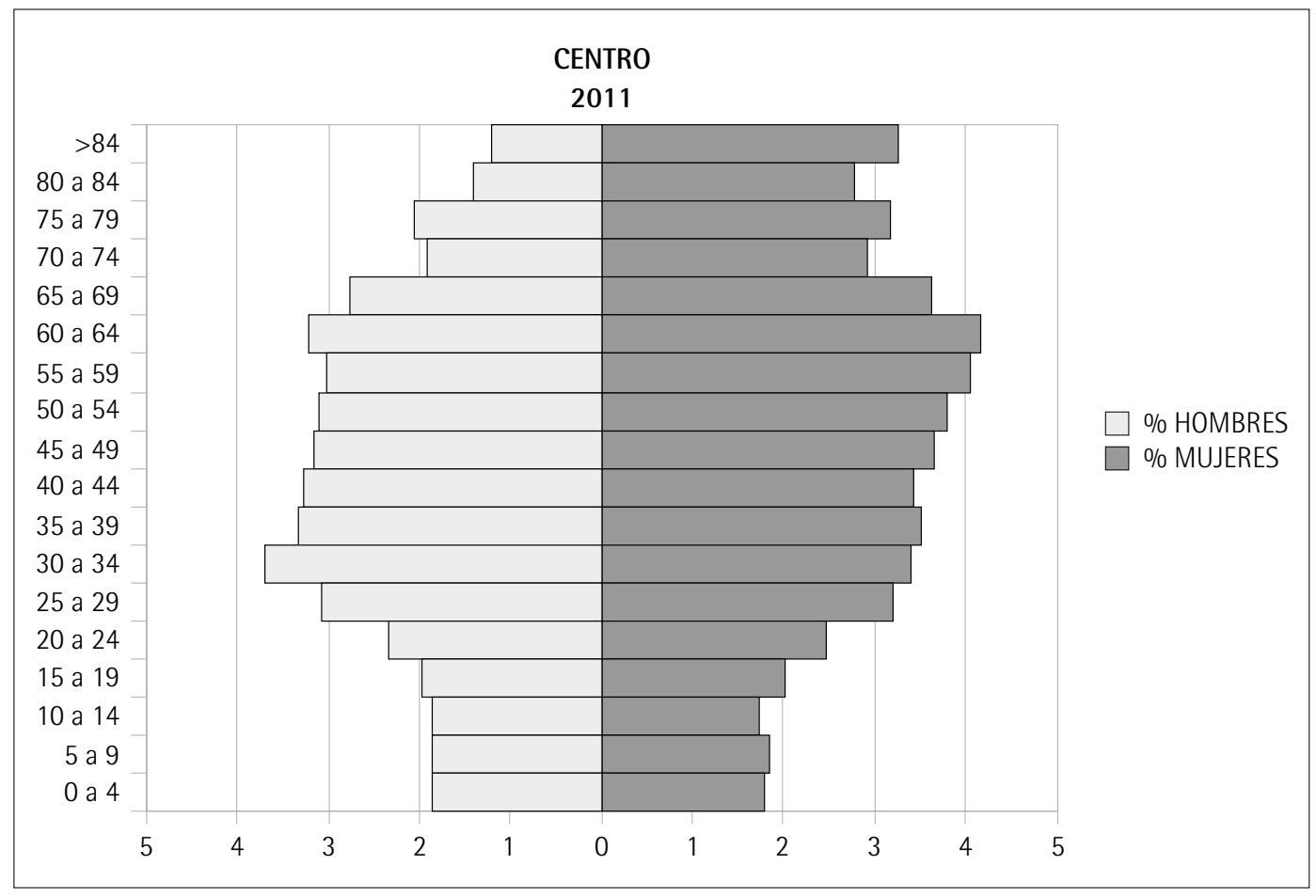

A GrÁfico 1. Pirámide de población del distrito Centro. Elaboración propia.

$\left({ }^{9}\right)$ INSTITUTO ARAGONÉS DE ESTADÍSTICA. Indicadores demográficos del Movimiento Natural de la Población Distritos censales del municipio de Zaragoza. Años 1996-2000. Zaragoza, IAEST, 2003. 
en 1996 su población era de 60.489, un 10,1\% del total de la ciudad, en el 2011 se reducía a 58.301 habitantes, el 9,5\%.

En su estructura cabe destacar, tal y como antes señalamos, el gran peso de la población vieja, los mayores de 65 años representan el 25,13\%. El contingente de jóvenes es muy reducido en relación a las cohortes de mayor edad, un 10,95\%, por ello la tasa de envejecimiento es la más alta de Zaragoza. La natalidad necesariamente ha de ser baja y sin posibilidad de reemplazar a las generaciones adultas. La esperanza de vida es muy elevada, el 5,49\% de la población tiene más de 84 años, por lo que con esta dinámica su peso seguirá aumentando a un ritmo cada vez más intenso.

La imagen de la pirámide (gráfica 1) nos presenta una estructura muy regresiva, en forma de columna, con un pronunciado estrechamiento en la base que se extiende de manera uniforme por los primeros grupos de edad, su tasa de masculinidad todavía no es demasiado desequilibrada aquí. Las cohortes medias presentan un perfil plano, sin salientes prominentes, aunque a partir de este punto comienza a bascular el peso del contingente femenino, iniciando el peso de los varones una reducción, muy apreciable a partir de los 64 años y exagerada en el grupo de más de 84 años donde se sitúa en el $37,25 \%$. Con esta estructura el crecimiento vegetativo es negativo y las posibilidades de recuperarlo mediante el crecimiento natural, escasas, pues tampoco se producen hoy aportes de población extranjera, que podrian aumentar la población y revertir el proceso.

El caso del Caso Histórico es similar, en él la población total asciende a 46.900 personas, un 7,2\% del total, la media de edad es de 42,85 años, el $51,22 \%$ son mujeres y el
$48,78 \%$ hombres. En cuanto a su pirámide de edad (gráfica 2), refleja la estructura de una población con una tasa de envejecimiento elevada, el 20,15\%, y con una forma particularmente regresiva, donde la base sólo representa el 12,26\%, aunque se ha visto ampliada por los comportamientos positivamente natalistas del contingente extranjero. La tasa de supervivencia en las mujeres del grupo de más de 80 años es alta, el colectivo representan más del $5 \%$ de la población total, lo que indica al mismo tiempo un alto índice de sobreenvejecimiento, mayor que el de los hombres en estos dos grupos de edad.

Los demás distritos incluídos en este grupo presentan estructuras parecidas, con un rítmo de envejecimiento notable, San José un 22,1\% en 2011 frente al 17,7\% en 2008, con una pérdida demográfica para el trienio del 1\%; Universidad comparte este descenso de población respecto a 2008, un 1,9\%, a la vez que sus valores de envejecimiento han pasado del 17,3\% al 22,3\%. Las Fuentes muestra un 21,54\%, $17 \%$ en 2008 , con un gran porcentaje de extranjeros, 9,9\%, que se ha visto reducido progresivamente, lo que explica su evolución. Delicias arroja cifras similares en las cohortes de más de 64 años, 21,37\%, 17\% en 2008; La Almozara un $20,7 \%, 12,8 \%$ en 2008; en ninguno de ellos el potencial demográfico, con la dinámica actual, puede suponer incrementos de población.

\subsubsection{Grupo 2. Distritos periféricos extremos, tasas medias de envejecimiento}

En un orden decreciente de sus niveles de población envejecida trataríamos en este apartado de los casos de

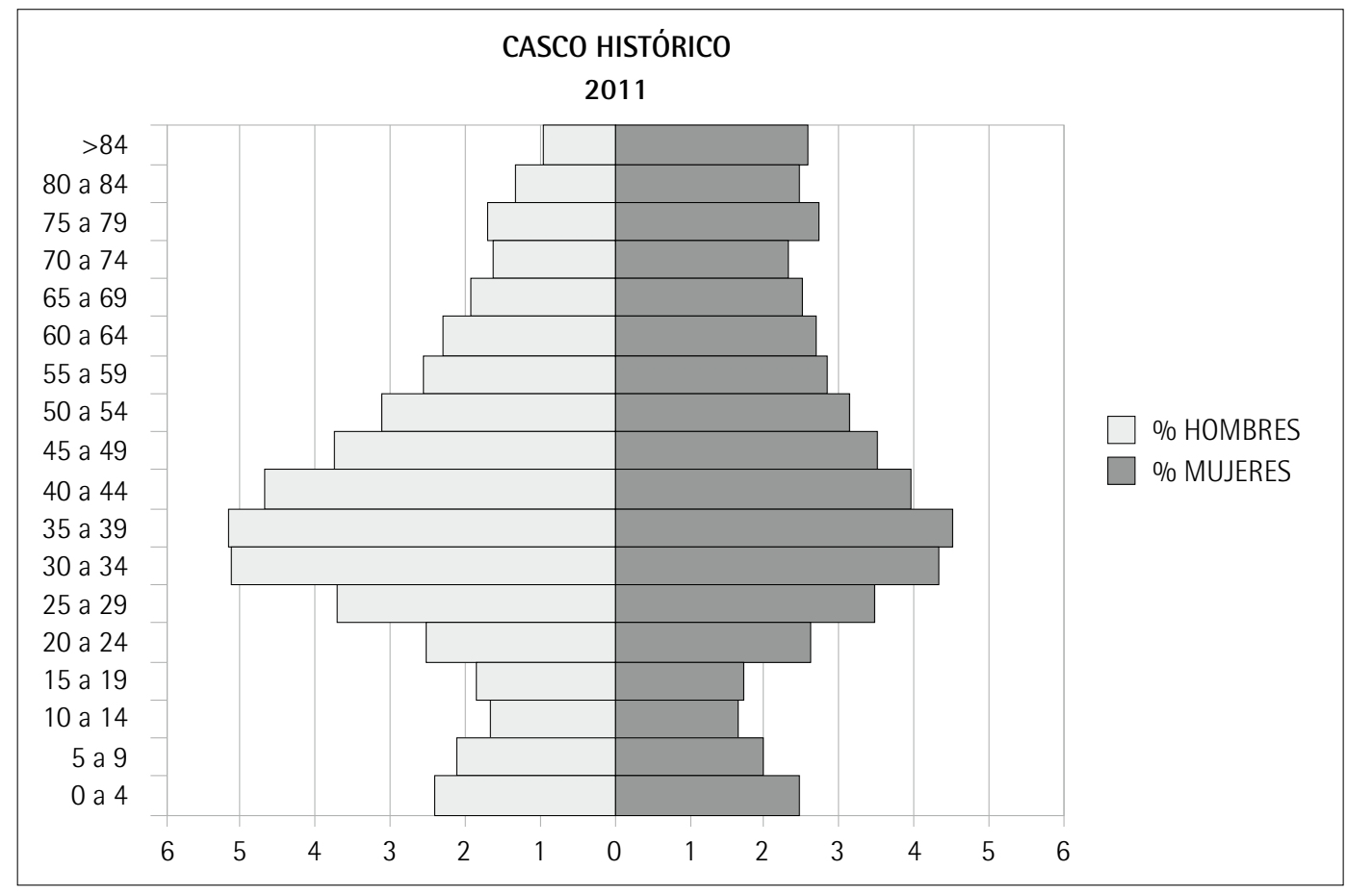

\ GrÁfico 2. Pirámide de población del distrito Casco Histórico. Elaboración propia. 


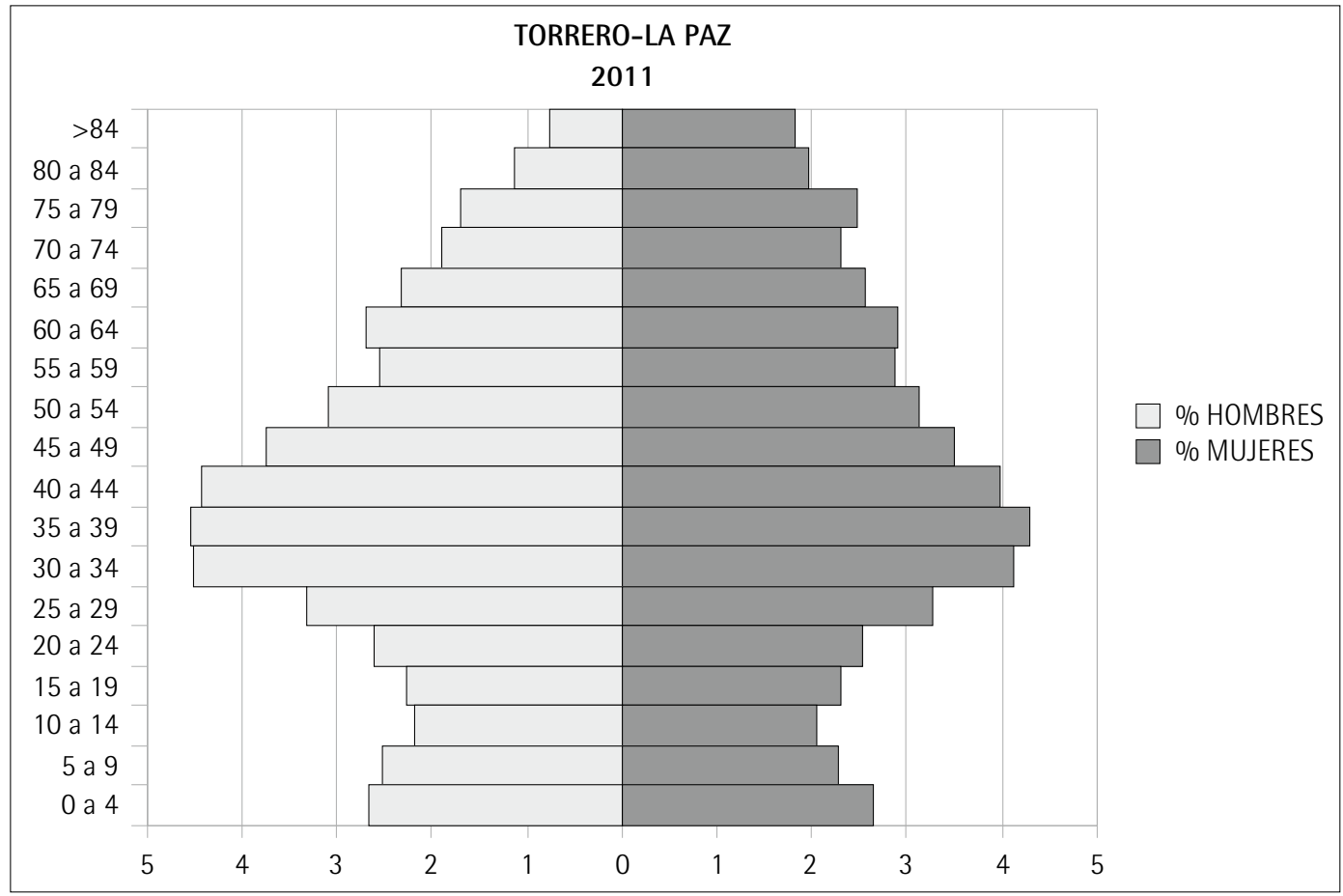

\ GRÁfico 3. Pirámide de población del distrito Torrero-La Paz. Elaboración propia.

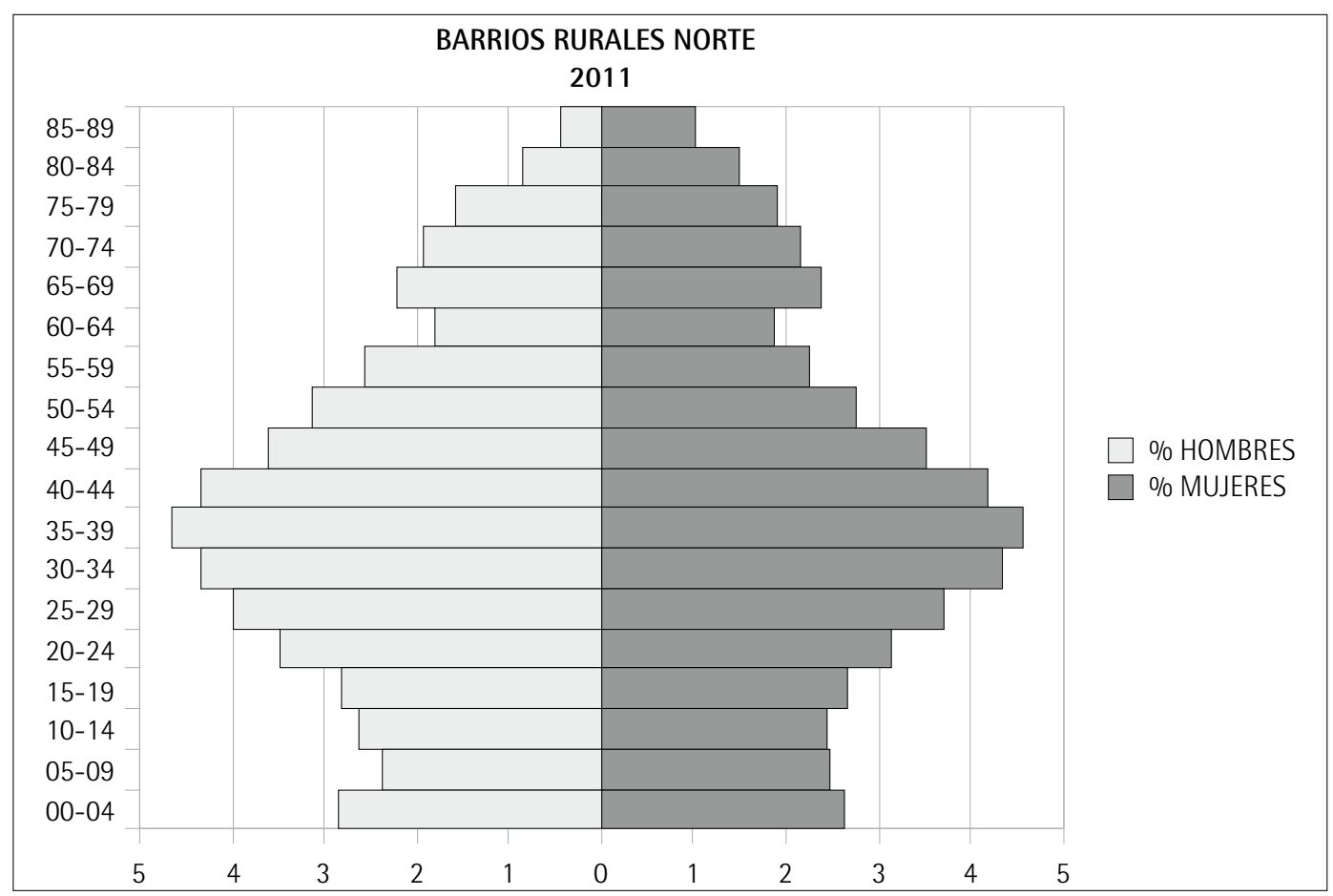

\ GRÁfICO 4. Pirámide de población del distrito Barrios Rurales Norte. Elaboración propia.

Torrero-La Paz, Barrios Rurales Norte y Oeste. En su conjunto no superan el 8,3\% de la población total de la ciudad y participan de unos porcentajes de entre el $16 \%$ y el $20 \%$ de grupos de más de 64 años. Sus densidades son mucho menores que las del grupo anterior pero todos han incrementado su población desde 2008 en porcentajes próximos al 0,5\%, aunque presentan una tendencia al estancamiento.
En Torrero-La Paz viven 36.854 habitantes según el padrón de 2011, con un crecimiento escaso, el 0,5\% desde 2008 (36.665). Su estructura incluye un 18,8\% de población de 0 a 19 años, cifras similares a las de $2008(18,77 \%)$, con un ritmo evolutivo tendente al estancamiento, además de apreciase un significativo aumento de los grupos mayores de 64 años, 18,8\% en 2011 frente a un 15,2\% en 2008. La 


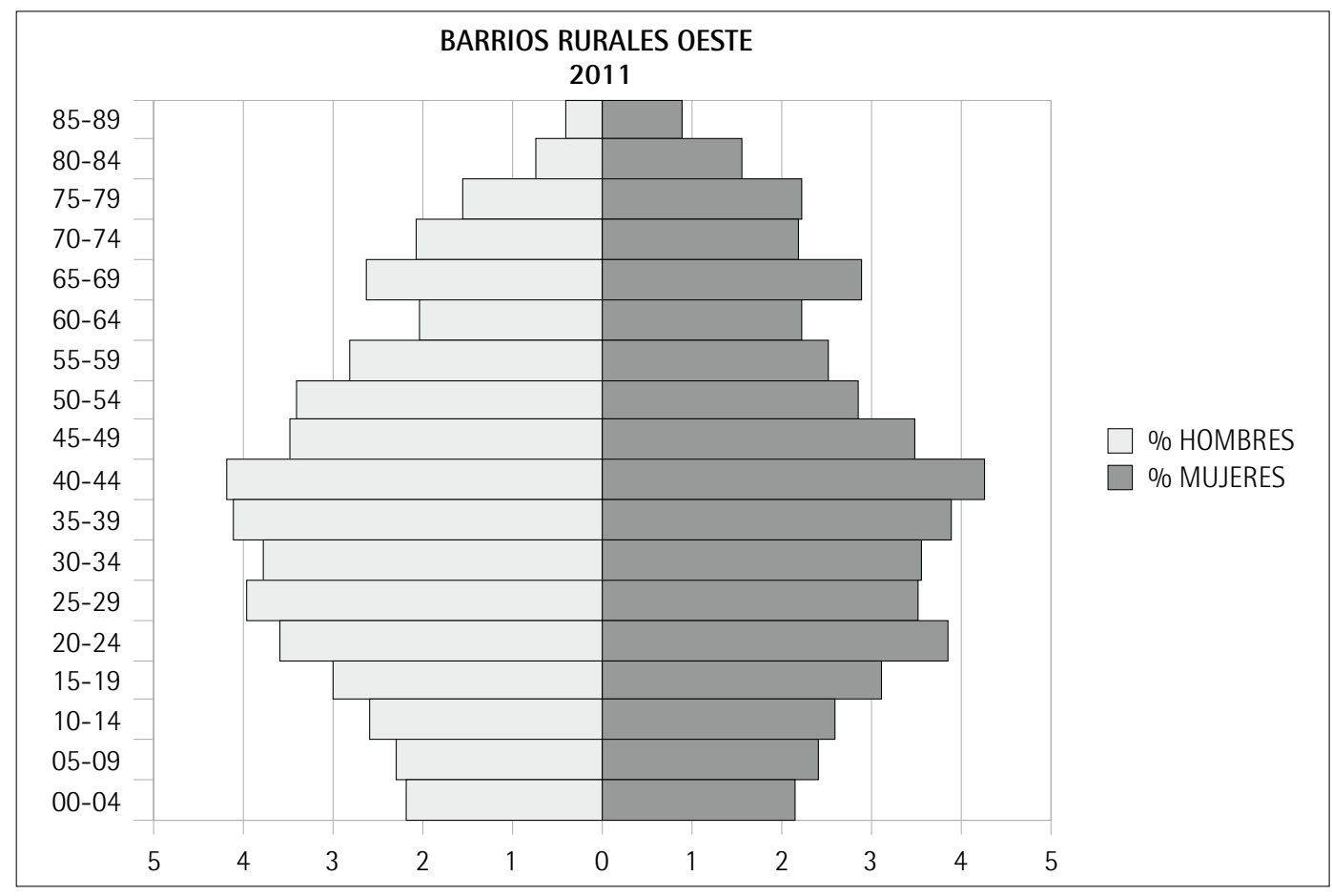

\ GRÁfICO 5. Pirámide de población del distrito Barrios Rurales Oeste. Elaboración propia.

relación de la base de su estructura demográfica con la cima indica una tendencia hacia la regresión, ya que el incremento de los primeros se mantiene plano respecto a 2008 , y los de la cúspide se han elevado de manera importante. Por otro lado, la sex ratio muestra un aumento del peso de las mujeres a partir de los 64 años, que se va haciendo cada vez más importante por encima de los 75 años.

En cuando a los Barrios Rurales Norte se incluyen en ellos un conjunto de barrios rurales situados en el límite norte del término municipal. Su población en 2011 era de 21.072 habitantes ${ }^{10}$, el $3 \%$ del total.

La pirámide de edades (gráfica 4) nos muestra una población en regresión demográfica, con una base estrecha, casi plana y una cúspide más gruesa, reflejo del envejecimiento instalado en la estructura.

Los Barrios Rurales Oeste se articulan sobre el eje de la carretera N-232 hacia Logroño, que es un pasillo industrial de primer orden. En 2011 su volumen demográfico ascendía a 12.436 habitantes, un $0,17 \%$ de la población de Zaragoza, de menor peso que el anterior distrito y con núcleos más pequeños. Los grupos de más de 64 años representan el $17,21 \%$, lo que implica que el índice de envejecimiento es mayor que en el distrito anterior y su natalidad inferior, como consecuencia su tendencia al envejecimiento se acelerará antes. Su estructura por edades (gráfica 5) nos muestra un perfil en forma de bulbo, más acusado que el del anterior distrito.

\subsubsection{Grupo 3. Distritos periféricos, bajas tasas relativas de envejecimiento}

Incluimos en este grupo aquellos que tienen menos de un 16\% de población de más de 64 años, Casablanca, Actur, El Rabal, Miralbueno, Oliver y Santa Isabel. Geográficamente la mayoría de ellos se localiza en una posición exterior del casco urbano, sus límites externos están marcados por los distritos rurales. Se incluyen aqui todos los de la margen izquierda del Ebro, que han sido el soporte de la reciente expansión urbana iniciada a mediados de los años 90, concentrando población joven con dinámicas natalistas, lo que ha provocado el vaciado de los distritos del grupo 1. Casi todos han visto incrementar su población en cifras superiores a un 5\% desde 2008.

En un gradiente descendente El Rabal ocupa el primer lugar, con los datos que nos ofrece el padrón municipal para los años 2008 y 2011 podemos observar que ha incrementado su población un 3,39\%, asi en 2008 vivían en la zona 76.150 habitantes, tres años más tarde eran 78.733. Su estructura refleja que el $24 \%$ es menor de 14 años, comparativamente mayor que otros distritos, frente al $14,25 \%$ de poblacion vieja. La masculinidad se va reduciendo progesivamente hacia la cúspide pero es mucho menos acentuada que en otras zonas. En la pirámide de población (gráfica 6) podemos observar que, aunque presente forma de bulbo y adquiera tendencia regresiva, la natalidad ha aumentado en

(10) Fuente: IAEST 2011. 


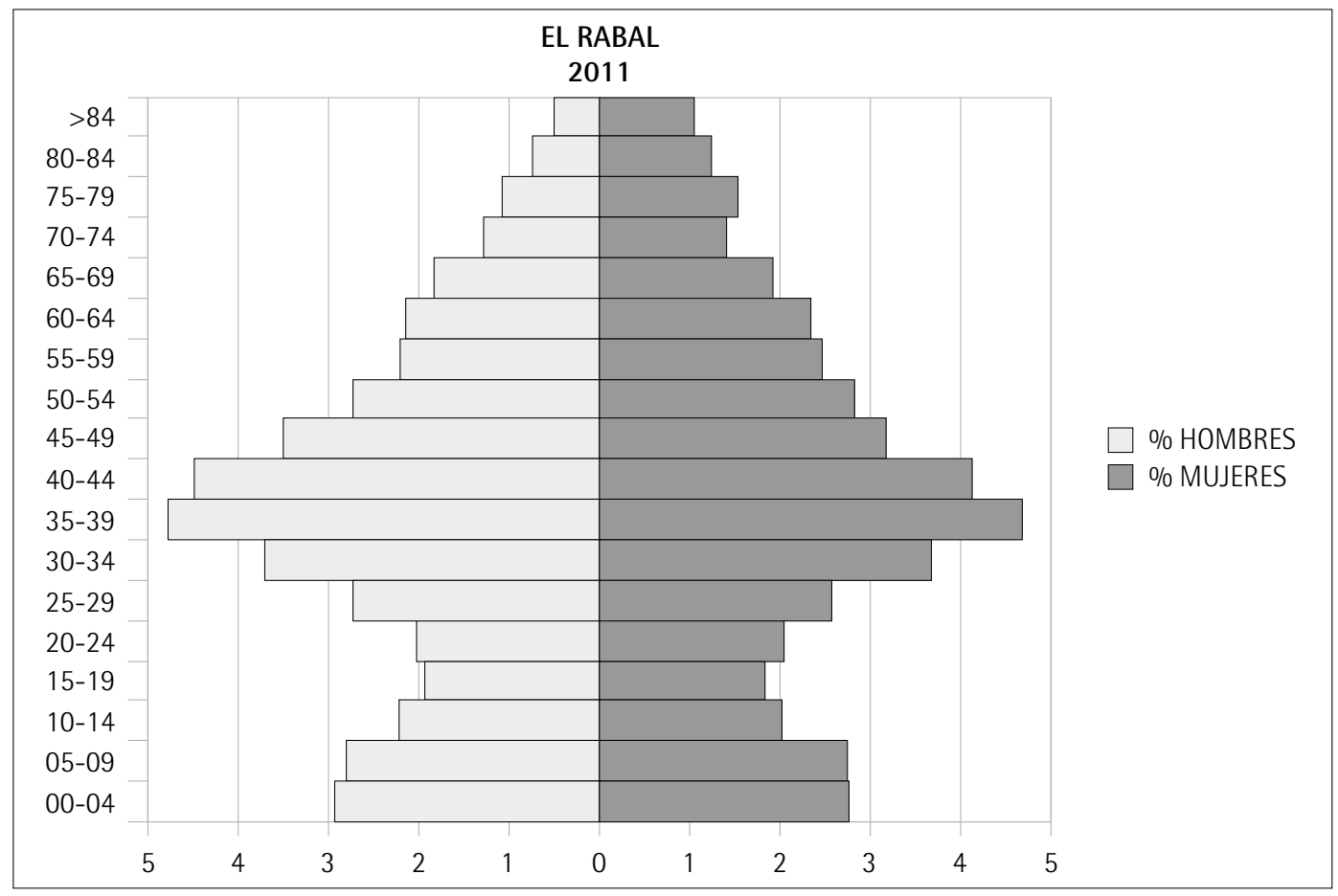

ム GrÁfICo 6. Pirámide de población del distrito El Rabal. Elaboración propia.

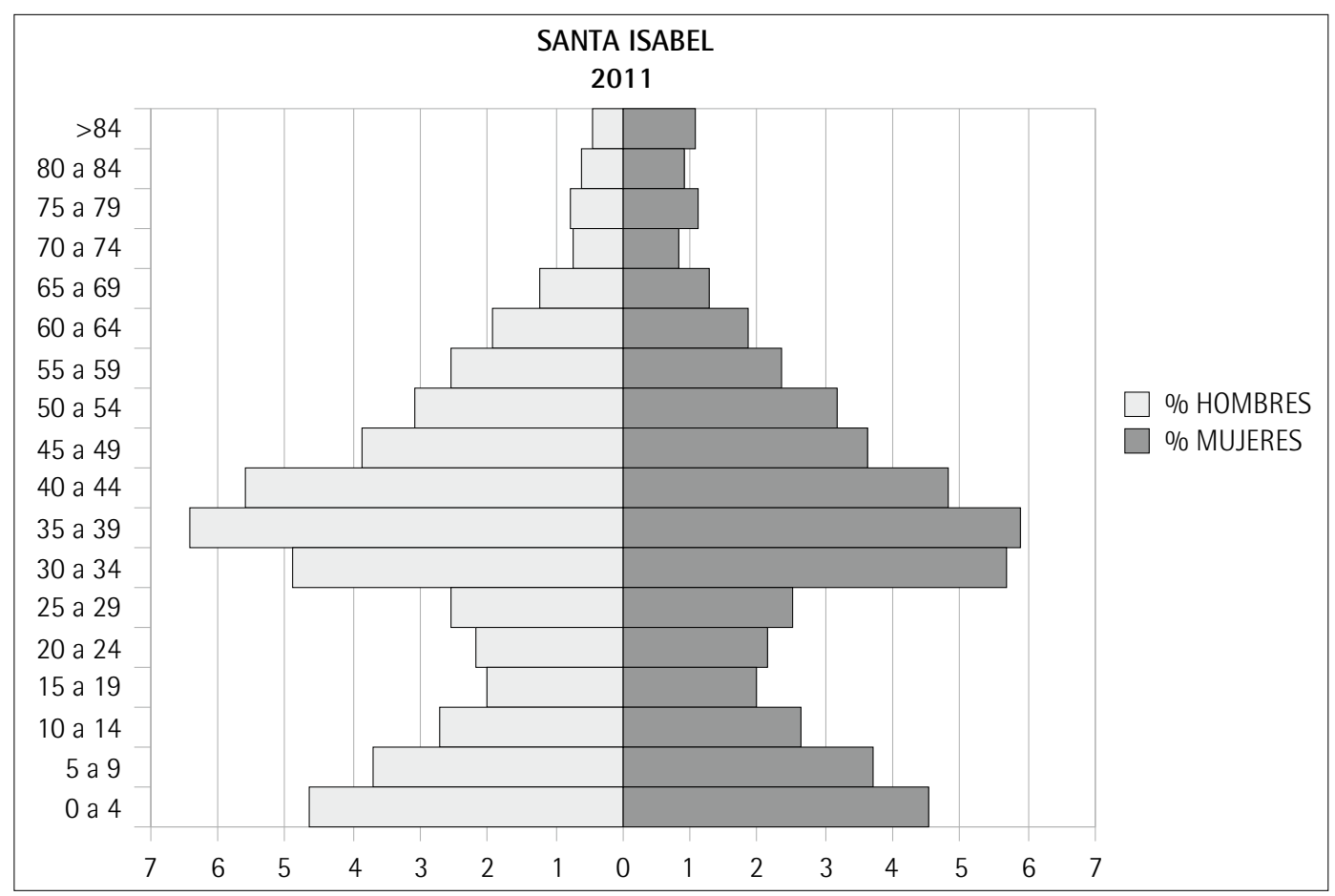

\ GRÁFICo 7. Pirámide de población del distrito Santa Isabel. Elaboración propia.

el último cuatrienio ensanchando la base. Las tasas de masculinidad se mantienen compensadas y comienzan a crecer sólo en los grupos superiores, fruto de la mayor mortalidad masculina.

El distrito Oliver, por su parte, ha pasado de 29.030 habitantes en 2008 a 30.658 en 2011, un incremento del 5,6\%, la población extranjera es un 14, $9 \%$ del total. Su estructura refleja que el 16,9\% es menor de 14 años frente al 12,6\% de población vieja. Los grupos de 30 a 44 son los que arrojan la mayor proporción, un 28,4\%, fruto de la llegada de inmigración y de residentes de otras zonas urbanas, lo que se refleja en un aumento de la natalidad durante los 2 últimos cuatrienios. La masculinidad se va reduciendo progresivamente hacia la cúspide pero con mayor grado de equilibrio, 


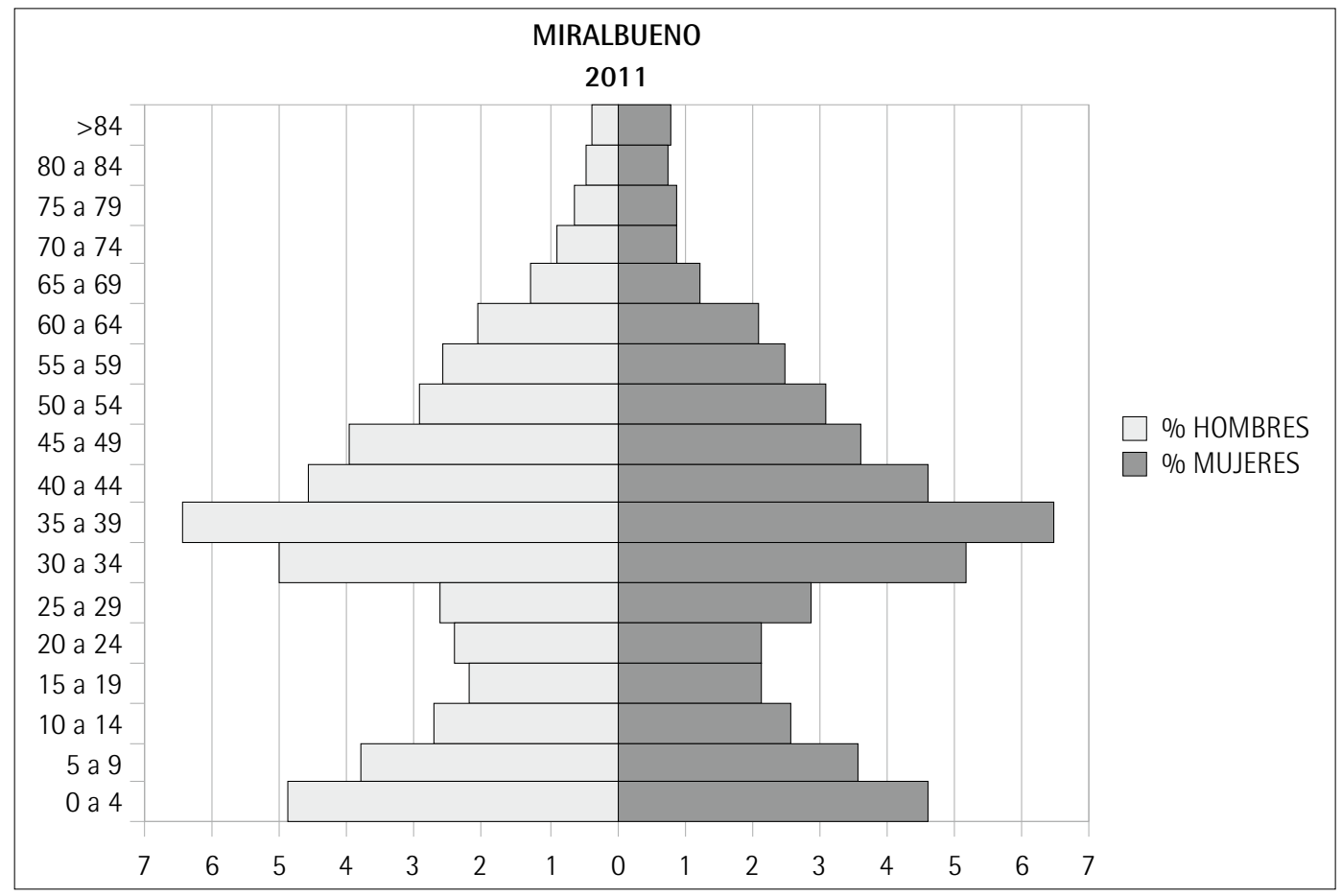

\ GRÁfico 8. Pirámide de población del distrito Miralbueno. Elaboración propia.

un 50,1\%, comenzando a crecer sólo en los grupos de edad superiores; el perfil de su pirámide de edades es muy similar al del distrito El Rabal.

Actur y Santa Isabel ofrecen unas proporciones de envejecimiento parejas, rondando el 10\%; Santa Isabel (gráfica 7) multiplicó su población a partir de finales de los años 90, cuando pasó de ser un distrito de características rurales a una zona residencial, el mismo fenómeno observado en Miralbueno. En 2008 contaba con 11.833 habitantes, pasando a los 12.844 en 2011, lo que se traduce en un $8,1 \%$ de crecimiento Es uno de los distritos más dinámicos, excelentemente comunicado y próximo al gran polígono industrial de Malpica. Si bien es cierto que su población mayor ha crecido del 7,2\% en 2008 al 10\% en 2011, del mismo modo los menores de 19 años han pasado del 23,7\% en 2008 al 25,8\% en 2011, por lo que cuenta con los índices de población joven más altos de Zaragoza y de envejecimiento más reducidos; el porcentaje de extranjeros no pasa del $5 \%$.

Por último, los dos distritos con tasas de envejecimiento más bajas corresponden a Casablanca y Miralbueno, 8,28\% y $8,04 \%$ respectivamente. En sus estructuras demográficas se reflejan los aportes de población joven alli asentadas a través de los grandes y recientes proyectos urbanísticos.

Para Miralbueno el padrón municipal de 2008 muestra unas cifras de 8.587 habitantes, pasando en 2011 a 10.068, un 17\% más, sobre todo jóvenes, por lo que su tasa de natalidad aumentó y la base de su pirámide se ha ensanchado, haciéndose porcentualmente más pequeña su cúspide, donde los mayores de 64 años tan sólo representan un 8,04\%, (un incremento del 0,9\% desde 2008). Los grupos de edad de 35 a 39 años, el 12,8\%, reflejan este aumento de población procedente de otros distritos, fundamentalmente española, tan sólo hay un 5,5\% de población extranjera.

80 años. En la pirámide (gráfica 8) observamos un crecimiento reciente de la base por el aumento de la natalidad, consecuencia a su vez del aporte de contingentes jóvenes en edad de procrear, y una cúspide pequeña, con un porcentaje de población envejecida mucho menor que en otros distritos. La masculinidad está equilibrada en un 49,8\%, aumentando en las cohortes superiores el porcentaje de mujeres, según el comportamiento demográfico natural.

Por último el distrito de Casablanca posee una extensión de $66 \mathrm{~km}^{2}$, lo que supone una densidad de $480 \mathrm{~h} / \mathrm{km}^{2}$, la más baja de los distritos urbanos. Sin embargo el crecimiento de la ciudad hacia esta zona significó la construcción de más de 15.000 viviendas, que comenzaron a entregarse en el año 2006. Por ello, su aumento demográfico ha sido enorme en términos porcentuales, así, según datos de 2008, el barrio contaba con 18.548 habitantes frente a los 31.647 de 2011, un incremento del 70,6\%. Esta circunstancia va a quedar reflejada en su estructura demográfica con un desmesurado aumento del grupo de entre 25 a 34 años que suma el 38,69\%, la consecuencia lógica es el repunte de los nacimientos. La pirámide es similar en su perfil a la del anterior, nos muestra una estructura que parece iniciar una recuperación de la natalidad, los mayores de 65 años representan un 8,28\%, con disimetria en la distribución por sexo, cuya tasa de feminidad es manifiestamente mayor a partir de los 75 años. 


\section{REPERCUSIÓN DEL ENVEJECIMIENTO EN LOS DIFERENTES ASPECTOS DEL PAISAJE URBANO}

Además de las inegables consecuencias socioeconómicas de este hecho, falta de reemplazo, aumento de la población dependiente, especialmente protagonizado por el colectivo de 80 y más años, nuestro trabajo enfatiza sobre sus efectos visibles en el paisaje urbano lo que es, al mismo tiempo, un análisis de la respuesta del propio municipio ante este problema. Por ello, desde este punto de vista, es fundamental también analizar la estructura de los hogares y el grado de equipamiento de los servicios básicos para estos grupos de edades, como son el sanitario, asistencial, transporte, servicios sociales, su grado de equipamiento por distritos, así como el nivel de intervención de las administraciones públicas en la conservación del patrimonio residencial y urbanístico.

\subsection{Porcentaje de población envejecida que} vive sola, número de personas por hogar $\mathrm{y}$ tasas de feminidad

Una de los efectos del envejecimiento es el incremento de personas mayores que viven solas así como el aumento del régimen de vivienda en propiedad entre estos colectivos.
Consideramos fundamental este dato puesto que uno de los factores del envejecimiento es el aumento de la longevidad, con los cambios que en cuanto a la estructura del hogar y cuestiones de dependencia lleva aparejado.

Si la tendencia general de los hogares zaragozanos es a estar compuestos cada vez por menos miembros, en el caso de los mayores la inclinación es a vivir solos (tabla 1) ${ }^{11}$, por ello el análisis de los datos nos hace colegir que los distritos con menor porcentaje de mayores que viven solos corresponden a los niveles medios y bajos de envejecimiento, Margen Izquierda (Actur y El Rabal ${ }^{12}$ ), La Almozara y Oliver. Por el contrario, en Casco Histórico y Centro el efecto se invierte, figuran entre los de mayor envejecimiento, con tasas de mayores que viven solos más elevadas y un número menor de personas por hogar. En La Almozara, Oliver y los dos Barrios Rurales se observan tasas de ocupación de hogar más altas, porque los volúmenes de población joven son mayores y la natalidad es más elevada, como consecuencia de ello conviven más personas en la misma vivienda. En ninguno de los casos se supera las 2,9 personas/hogar, media española en 2001, llegando en algunos casos hasta las 2,4 (Casco Viejo) y 2,6 (Centro).

Del mismo modo las consecuencias del sobreenvejecimiento se manifiestan directamente en el desequilibrio de la sex ratio, aumentando sensiblemente las tasas de feminidad, que en los otros grupos de edad se muestran equilibradas.

\begin{tabular}{|l|c|c|c|}
\hline \multicolumn{1}{|c|}{ DISTRITOS } & \%+64 años & \% Visen solos & 2,4 \\
\hline CASCO HIST & 24 & 14,3 & 2,6 \\
\hline CENTRO & 22,9 & 14,1 & 2,6 \\
\hline DELICIAS & 20,1 & 11,2 & 2,7 \\
\hline UNIVERSIDAD & 20,05 & 11,5 & 2,6 \\
\hline SAN JO SE & 20,5 & 11,9 & 2,7 \\
\hline LAS FUENTES & 19,3 & 10,7 & 2,9 \\
\hline LA ALMOZARA & 12,8 & 7 & 2,9 \\
\hline OLIVER•VALDE & 12,9 & 7,4 & 2,7 \\
\hline TORRERO & 21,5 & 11,1 & 2,8 \\
\hline MARGEN IZDA. & 10,5 & 5,3 & 2,9 \\
\hline B. RURALES N. & 16,8 & 7,8 & 2,9 \\
\hline B. RURALES 0. & 18 & 8,7 & \\
\hline
\end{tabular}

$\Delta$ TABla 1. Comparativa entre el grado de envejecimiento, \% de mayores que viven solos y $\mathbf{n} .^{\circ}$ de personas por hogar. Datos IAEST, Censo de Población y Vivienda 2001. Elaboración propia.

(11) En este caso los datos de los porcentajes de población mayor de 64 años son los del IAEST para el año 2001. Al no hallarse todavía publicado el Censo de Población y Viviendas de 2011 hemos considerado la oportunidad de reflejar los datos de estructura de población también para este año 2001. En él podemos observar la variación de los porcentajes de población respecto a los de 2011, así distritos como Casco Antiguo han visto reducidas sus tasas de envejecimiento, fundamentalmente por aporte de población inmigrante, pasando de ser el más envejecido en 2001 a ser superado por el distrito Centro cuya tasa, en estos momentos, es la más alta, el 25\%. Del mismo modo Torrero-La Paz, La Almozara, San José, Las Fuentes, Delicias, han visto crecer significativamente sus porcentajes de envejecimiento desde 2001. Otros, como los Barrios Rurales Norte y Oeste, no se han visto afectados y mantienen unas cifras similares en ambos periodos.

(12) El distrito censal Margen Izquierda (IAEST) corresponde a la suma de los distritos municipales de Actur y El Rabal que ofrecen los datos de la Unidad de Estadistica y Gestión Padronal del Ayuntamiento de Zaragoza. 
Zaragoza nos ofrece un escenario general en el que las tasas de masculinidad están niveladas en los estratos de 65 a 69 años, a partir de aquí el porcentaje de mujeres se eleva considerablemente en la misma medida que la edad. Los distritos en donde mayores diferencias se observan son los de Centro, La Paz, San José, Las Fuentes, Delicias (70 hombres por cada 100 mujeres) y Universidad, donde existe una gran disimetría (el índice de feminidad es de un 158,9\%). Por contra el mayor equilibrio lo observamos distritos de los grupos 2 y 3 , con niveles bajos o medios de envejecimiento, como son los Barrios Rurales Norte, seguido de Oliver-Valdefierro, Miralbueno, La Almozara, Casablanca y Actur.

\subsection{Equipamientos, Servicios y Accesibilidad}

Las especiales características de este tipo de población exigen una respuesta por parte de los municipios, adaptando los equipamientos, multiplicando su nivel de asistencia o creando nuevos servicios que den satisfacción a las necesidades especificas de la población envejecida. Por otro lado esta respuesta municipal va configurando y modificando el espacio urbano con actuaciones locales, que afectan a cada distrito, o generales y continuas en el espacio, como las relacionadas con las vías de comunicación, transporte colectivo, viario, etc. Obviamente, en algunos casos, el sólo hecho del envejecimiento no explica por sí solo una u otra actuación pero sí que la condiciona de manera específica, como la distribución de las paradas de transporte colectivo, el incremento de camas en la red sanitaria, el refuerzo de especialistas en los centros de salud, etc.

\subsubsection{Equipamiento sanitario y residencial}

Es inevitable que los incrementos en las tasas de envejecimiento condicionen las inversiones en equipamiento sanitario y residencial, puesto que estadísticamente son los grupos de edad que más uso hacen de este tipo de instalaciones, el aumento de este colectivo ha condicionado el aumento de las plazas hospitalarias, de la infraestructura sanitaria y asistencial y en definitiva de su distribución. En este sentido ${ }^{13}$ la ciudad ofrece 9 hospitales públicos, 3 de ellos de referencia, Hospital M. Servet, Clínico Universitario y Royo Villanova; 8 de iniciativa privada, con un número de camas que suman 3.972 repartidas de la siguiente forma:

- Sector público 75,3\%.

- Un 20,1\% es gestionado por la iniciativa privada, 799 camas. De éstas el 59\% son de instituciones no lucrativas, vinculadas a órdenes religiosas de la iglesia católica, y el $41 \%$ pertenecen a empresas no benéficas.

- El $4,6 \%$ propiedad de mutuas de accidentes de trabajo y enfermedades profesionales.

Los equipamientos sanitarios se completan con los centros de atención primaria de cada distrito (tabla 2), más numerosos entre los de mayor volumen de población neta

\begin{tabular}{|c|c|c|c|}
\hline DISTRITO & $\begin{array}{l}\text { N. }{ }^{\circ} \text { Camas } \\
\text { Hospital }\end{array}$ & Centros salud & $\mathrm{N}^{\circ}$ Plazas Geriátricas \\
\hline ACTUR - REY FERNANDO & 182 & 3 & 464 \\
\hline CASABLANCA & 354 & 1 & 642 \\
\hline CASCO HISTÓRICO & 95 & 3 & 399 \\
\hline CENTRO & 0 & 3 & 493 \\
\hline DELICIAS & 285 & 4 & 196 \\
\hline EL RABAL & 0 & 4 & 559 \\
\hline LA ALMOZARA & 0 & 1 & 93 \\
\hline LAS FUENTES & 0 & 2 & 94 \\
\hline MRALBUENO & 0 & 1 & 79 \\
\hline OLIVER - VALDEFIERRO & 0 & 3 & 194 \\
\hline SAN JOSÉ & 0 & 3 & 285 \\
\hline SANTA ISABEL & 0 & 1 & 158 \\
\hline TORRERO & 0 & 1 & 236 \\
\hline UNIVERSIDAD & 2450 & 4 & 590 \\
\hline RURAL & 0 & 9 & 1166 \\
\hline
\end{tabular}

$\Delta$ TABLA 2. Resumen equipamiento sanitario y geriátrico. Elaboración propia. 


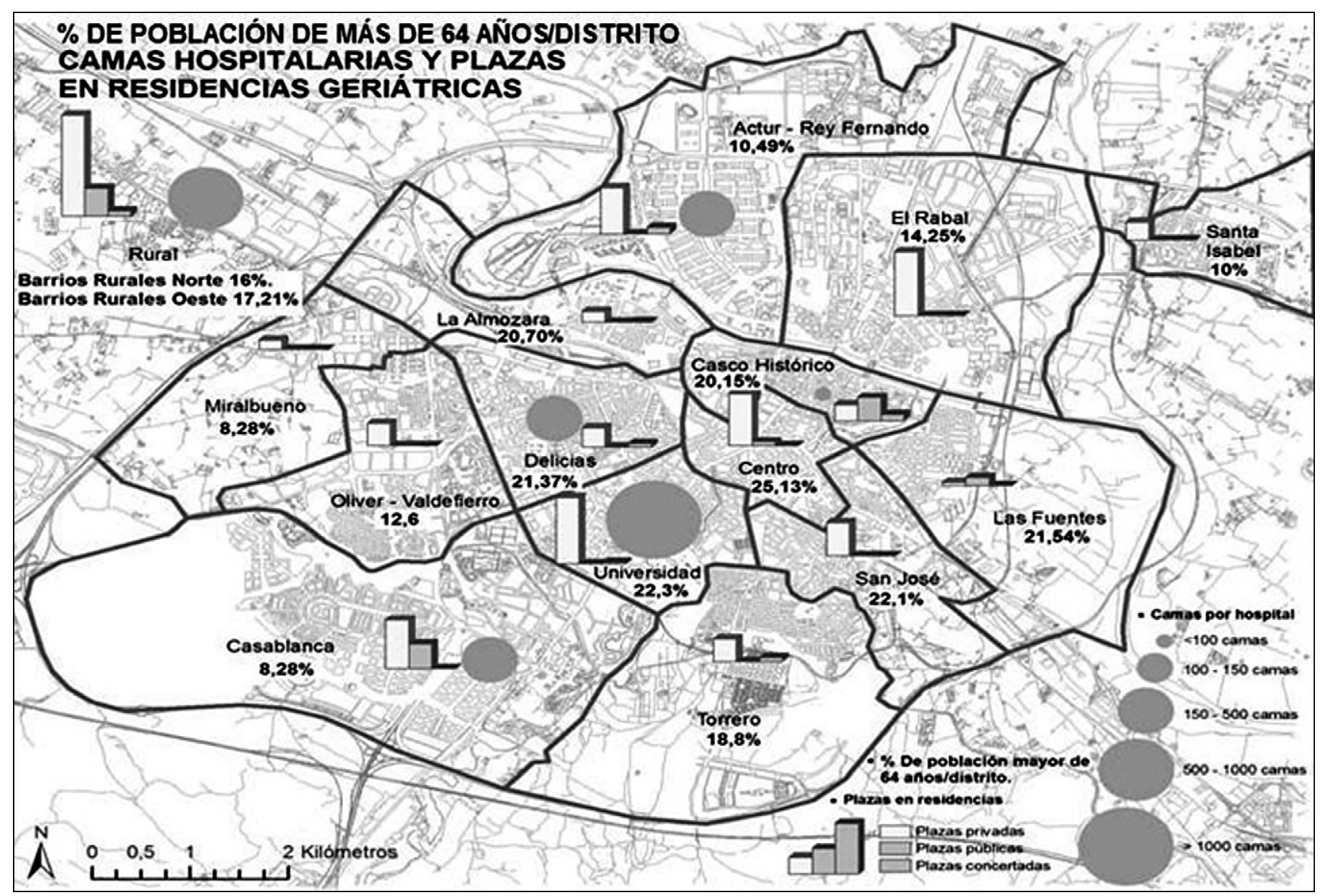

\ FIgURA 2. Equipamiento sanitario y residencial por distritos. Fuentes IASS, IAEST, Ayuntamiento. Elaboración propia.

y envejecida, como Delicias con 4 centros, Casco Antiguo y Centro con 3, pero claramente insuficientes en otros con un volumen demográfico y nivel de envejecimiento comparativamente elevado, como Las Fuentes, 2 centros, o Torrero-La Paz, 1. Un tercer grupo presenta un exceso relativo de oferta como es el caso de Actur, 4 centros de atención primaria, para una población de menor tamaño, menos dependiente de estos servicios y con un bajo envejecimiento.

El 4,6\% de los hogares de la ciudad tienen a alguna persona con discapacidad o limitación, mayoritariamente ancianos, siendo la zona sanitaria Zaragoza I ${ }^{14}$ (distritos de San José, Torrero-La Paz, Casablanca, Universidad, La Almozara, Las Fuentes, Casco Antiguo y Centro), el sector con mayor porcentaje, un 7\%. Las ratios del gobierno de Aragón establecen un médico de familia por cada 1.187 habitantes pero en Zaragoza la mayor parte de los titulares atienden entre 1.500 y 2.000 tarjetas sanitarias ${ }^{15}$, por lo que podemos concluir que, en el caso de este tipo del asistencia existe un cierto desajuste zonal, por un lado observamos un nivel de exigencia alto frente a una oferta claramente deficitaria en Las Fuentes, Casco Antiguo, Centro y Torrero-La Paz.

En lo referente al aspecto de la asistencia geriátrica, según datos del I.A.S.S. ${ }^{16}$ encontramos un total de 142 residencias (mapa 2) de las que 102 son de carácter privado, la gran mayoría con fines lucrativos (78,9\%) y sólo el $17,6 \%$ gratuitas, del conjunto el 9,3\% son concertadas. Las de carácter público equivalen al 4,2\% restante, propiedad del Gobierno de la Comunidad de Aragón y Ayuntamiento de Zaragoza.

Por distritos el mayor número de plazas corresponde a Barrios Rurales (1.166, un 20,6\%), el menor precio del suelo y el entorno natural son las claves de su ubicación y no su demanda real, son los mejor dotados, sobre todo en plazas privadas; le siguen Casablanca (642 plazas, un 11,3\%), Universidad (590, un 10,4\%), el Rabal $(559,9,8 \%$ ) y Centro $(458,8,1 \%)$. Los de menor dotación son los de La Almozara (93 plazas, un 1,6\%), Las Fuentes (94, un 1,5\%) y Miralbueno $(79$, un 1,3\%). Existe pues una deficiente oferta en

(14) Servicio Aragonés de Salud. Datos para 2011.

(15) GOBIERNO DE ARAGÓN: Estado de salud de la población aragonesa, sus determinantes y las actuaciones del Departamento de Salud y Consumo, 2010. Zaragoza, Gobierno de Aragón, p.12.

http://www.aragon.es/estaticos/GobiernoAragon/Temas/Familias/Documentos/EstadoSaludPoblacionAragon_sintesis.pdf

(16) Instituto Aragonés de Servicios Sociales. 
zonas como Centro, Universidad y Las Fuentes, mientras que en otras, como Casablanca, hay una sobredotación.

\subsubsection{La red de asistencia social}

La implementación y la complejidad de la red de asistencia social están muy condicionadas por el grado de envejecimiento de la población puesto que, aunque este tipo de colectivo no es usuario exclusivo, sí influye en las prestaciones de ciertos servicios. La red local de servicios sociales la integran, entre otros elementos, los Centros Municipales de Servicios Sociales (CMSS), 16 centros urbanos y 12 en barrios rurales con especial atención a los casos crónicos y de personas mayores, que intenta paliar el problema de la insuficiencia de recursos económicos, con dos instituciones, los 14 apartamentos para personas mayores de 65 años, destinados a que mayores sin recursos económicos puedan vivir por su cuenta y la residencia municipal, Casa de Amparo, que proporciona vivienda permanente y presta asistencia integral y continuada.

Por otro lado en el caso de contingencias de carácter temporal funciona el Servicio de Ayuda a Domicilio, que supone la prestación de una serie de atenciones de carácter personal, doméstico y social a los individuos o familias en su domicilio, corresponden al Servicio de Teleasistencia Domiciliaria y al Servicio de Apoyo al Cuidador (Programa Respiro), que ofrece la sustitución o apoyo provisional a los cuidadores habituales de alguna persona dependiente.

Según los últimos datos disponibles en el Ayuntamiento de Zaragoza ${ }^{17}$, los distritos que más demandaron este tipo de ayudas fueron Arrabal (El Rabal), San José y Delicias, donde se dedicaron $3.880,3.710$ y 3.732 horas de asistencia en ayuda a domicilio. En teleasistencia San José (501 usuarios) y Delicias (359) fueron los distritos con mayor nivel de prestación, siendo el polo opuesto Actur y Barrios Rurales Oeste con 113 y 140 usuarios respectivamente. En el programa de ayuda al cuidador el nivel de prestación es, por distritos, parejo a los anteriores, siendo Delicias y San José los que ofrecen un mayor volumen de demanda, 1.363 y 1.032 usuarios.

\subsubsection{Transporte colectivo y accesibilidad}

El transporte estructura la ciudad al igual que la red vial y peatonal estructura el barrio, ambas escalas, bien diseñadas, se apoyan mutuamente, a mayor libertad de trasladarse, más calidad de vida para el mayor.

De los tres principales vectores del transporte público (mapa 3), a excepción del taxi, el de mayor impacto en el espacio lo detenta el autobús urbano. Actualmente la flota de Zaragoza está compuesta por unos 380 vehículos ${ }^{18}$ que tienen de media una antigüedad de 7,43 años, una edad que comparte la mayoría de empresas de transporte urbano del estado. En la red hay líneas que circulan cada 11, 12, 13 ó 19 minutos. Ya hace unos años que se han implementado en la vía pública plataformas de hormigón para facilitar la accesibilidad. Las líneas con mayor volumen de transporte son las que unen los distritos Delicias, Centro, Universidad y Casablanca, los de mayor población neta (Delicias tiene más de 100.000 habitantes) con los principales centros sanitarios, administrativos, culturales y comerciales. Entre este tipo de transporte podemos destacar, como exclusivo para colectivos con problemas de movilidad, los 10 minibuses P.M.R.S. (personas con movilidad reducida severa), que están dedicados al transporte de discapacitados, en 2011 el balance sumó 2.288 usuarios, con 82.611 servicios y 44.139 horas de funcionamiento ${ }^{19}$.

El resto de la red de transporte colectivo, tranvía y red de cercanías, es nuevo y actualmente en fase de construcción, aunque existen en funcionamiento una línea de tren cercanías hacia los Barrios Rurales Oeste y otra de tranvía desde el distrito Centro hacia el sur, que atraviesa el de Universidad, hasta finalizar en el límite exterior del de Casablanca (barrio de Valdespartera) (mapa 3).

\subsubsection{Dotación de equipamientos y servicios para mayores de 64 años}

Los indicadores de equipamientos, como el de cobertura sanitaria, servicios asistenciales, centros de día y plazas públicas residenciales, plantean dos situaciones, por un lado la cobertura institucional, que se realiza por criterios de demanda, por otro la cobertura privada, por criterios economicistas. En materia asistencial sanitaria encontramos una distribución desigual de los servicios, así como en lo que se refiere a plazas geriátricas que, como ha quedado patente, adolece de una insuficiencia de plazas públicas y escasa dotación de concertadas; en centros de día, el índice para el año 2011 se sitúa en 0,29 plazas por cada 100 habitantes, con mayor implementación que en el resto de la provincia, 0,14.

En términos generales el envejecimiento ha condicionado el incremento de los recursos asistenciales para mayores pero todavía de forma insuficiente en los que posibilitan niveles de autonomía más altos y de mantenimiento de estos colectivos en su propio medio, como son los centros de día. En plazas residenciales debe de incrementarse la oferta pública para garantizar una asistencia adecuada, del mismo modo que la de los servicios de teleasistencia y de ayuda a domicilio donde, a la vista de la creciente demanda, se observan unos niveles de prestación mejorables. Las consecuencias del envejecimiento están íntimamente relacio-

(17) Centro Municipal de Servicios Sociales. Ayuntamiento de Zaragoza. Datos referidos a 2009.

(18) Fuente TUZSA, Transportes Urbanos de Zaragoza, 2011.

(19) Fuente Área de Transportes del Ayuntamiento de Zaragoza, 2011. 


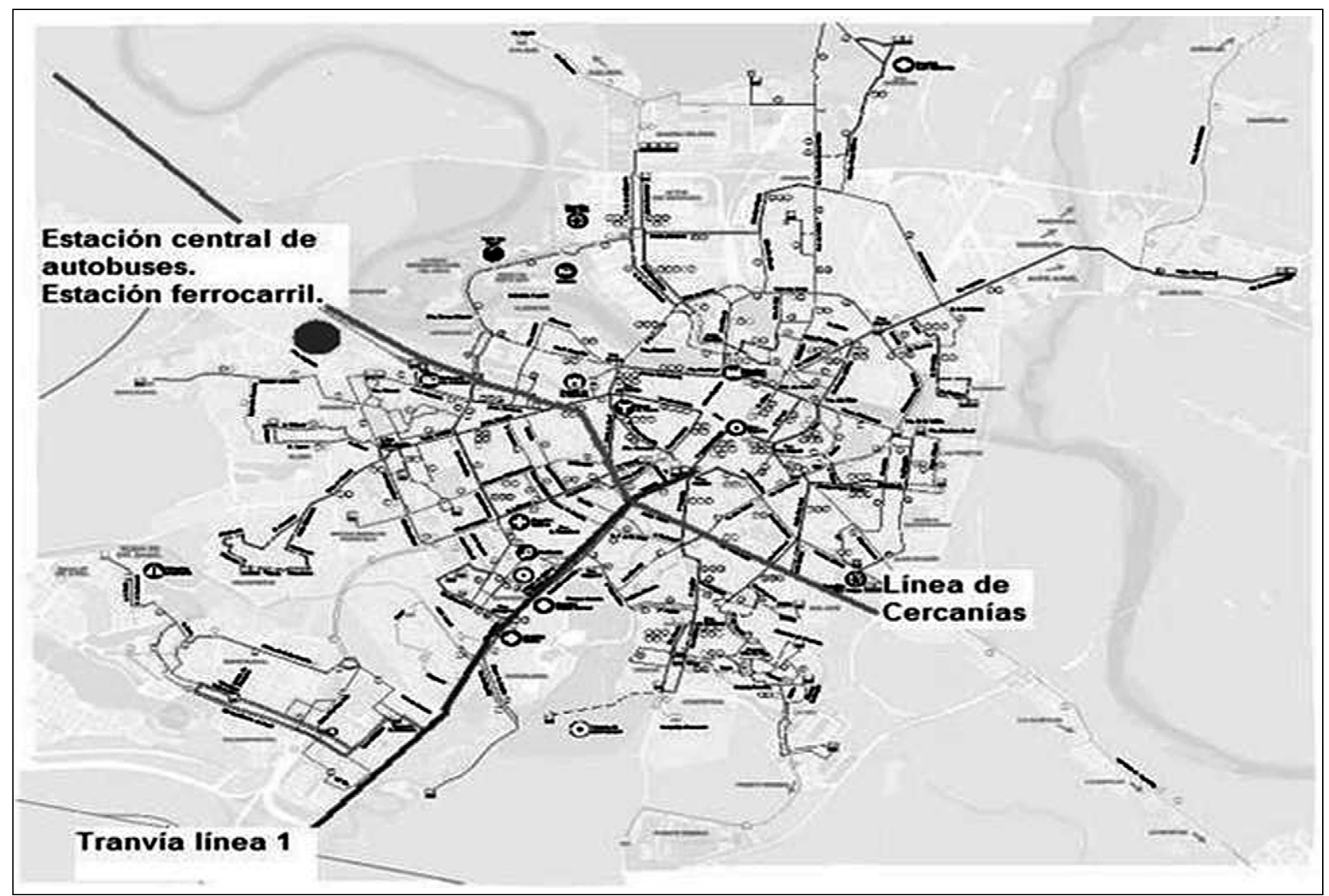

$\Delta$ Figura 3. Red de transporte urbano de Zaragoza. Fuente TUZSA. Elaboración propia.

nadas con los índices de dotación de servicios específicos para cada zona. Según este criterio, los relacionados con la salud tienen una distribución fijada por el Gobierno de Aragón, pero debemos de tener en cuenta que los hospitales de referencia no sólo atienden a población urbana sino que extienden el servicio a toda la provincia. Por centros de salud, los distritos mejor dotados son los de Miralbueno y Oliver (1 centro por cada 10.000 habitantes), le siguen Santa Isabel y Universidad (1 cada 12.000), Casco Antiguo (1 cada 15.000) Actur, Centro y El Rabal (1 cada 19.000). Los peor tratados son Casablanca (1 cada 31.000) y Torrero (1 cada 36.000). Los Barrios Rurales, con una población de 33.500 habitantes sólo tienen uno pero está apoyado con 9 consultorios ( 1 por cada 3.722 habitantes).

La dotación de plazas en residencias geriátricas está condicionada mayoritariamente por la iniciativa privada, es la mayor propietaria de plazas, que no actúa con los mismos criterios de distribución que las administraciones públicas, por el contrario busca, entre otros, el menor precio del suelo, por ello observamos que la mayor parte de las plazas se concentran en el distrito rural (3,4 plazas por cada 100 habitantes). En los otros esta tendencia se rompe bruscamente, Casablanca presenta un índice de 2 plazas por cada 100 habitantes, El Rabal 0,7, Torrero 0,6 y los peores dotados son Las Fuentes con 0,02, La Almozara y Miralbueno. Las consecuencias del proceso se hacen sentir en la demanda de servicios sociales que, tal y como refleja el Documento Base del Plan Director-Estratégico de Servicios Sociales de la ciudad de Zaragoza 2011-2020 ${ }^{20}$, se ha visto incrementada entre un $61 \%$ y un $64 \%$ desde el inicio de la crisis económica, siendo este aumento muy superior en las prestaciones básicas ${ }^{21}$. De otro lado si analizamos los principales índices de cobertura para estos los grupos de edad avanzados, el Informe de Indicadores ${ }^{22}$, en referencia a los centros de día, nos muestra que el nivel de satisfacción en la ciudad es del 0,29\%, menor que el umbral de referencia en España, $0,34 \% \%^{23}$, y aunque

(20) SERVICIO DE PLANIFICACIÓN Y ORDENACIÓN DE SERVICIOS SOCIALES: Plan Estratégico de Servicios Sociales de Aragón 2012-2015. Diagnóstico de situación (Borrador). Zaragoza, Gobierno de Aragón, 2011, pp. 60-75.

(21) El Documento Base del Plan Director-Estratégico de Servicios Sociales, Ciudad de Zaragoza 2011-2020 sitúa el aumento de la demanda en el caso del ingreso aragonés de inserción en torno al 409\% y en torno al 168\% en el caso de las Ayudas de Urgencia.

(22) EBRÓPOLIS.: Sistema de Indicadores de Seguimiento del Plan Estratégico de Zaragoza y su entorno. Informe 2010. Zaragoza, Ebrópolis, 2011.

(23) İndice de cobertura $=\left(\right.$ plazas/pob. $>65$ años) $\left.{ }^{*} 100\right]$ 


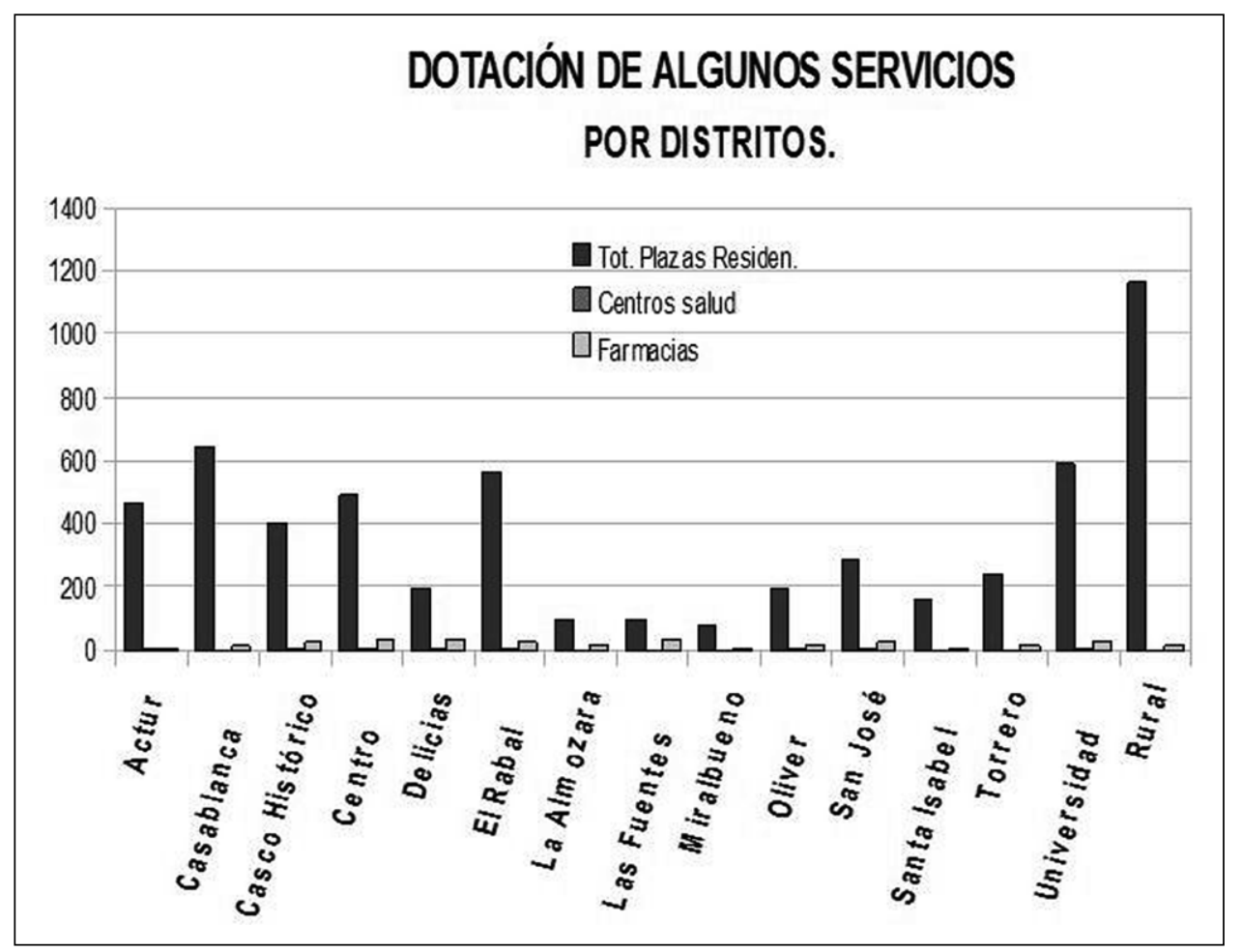

ム GrÁfico 9. Dotación de equipamientos por distritos.

desde 2008 haya aumentado un 0,4\%, todavía se observa un déficit importante en la oferta del servicio.

Otro indicador con gran importancia para el colectivo es el número de cartillas por profesional sanitario ${ }^{24}$. El objetivo medio se sitúa en las 1.500 cartillas/médico, la ratio de Zaragoza, en 2010 llega a $1.579^{25}$ pero en un análisis por distritos detectamos ratios excesivas, con la consecuente merma en la calidad asistencial, en Casablanca, algunas áreas puntuales del distrito como Valdespartera alcanzan las 2.390 cartillas/médico. También son elevadas en Torrero-La Paz (1.700), Casco Histórico, Centro (en torno a las 1.600) y con un buen nivel en Las Fuentes (1.380) y Delicias (1.425), el resto se sitúan en el umbral de las 1.500.

\section{LA HUELLA POBLACIONAL EN EL PAISAJE URBANO}

El envejecimiento de la población tiene su efecto más visible en las actuaciones sobre el paisaje urbano, en algunos casos este fenómeno no motiva por sí solo su transformación pero es, en otros, la causa inmediata. Para el Gobierno de Aragón se entienden como áreas de renovación urbana "los barrios o conjuntos de edificios que precisan de actuaciones de demolición y sustitución de los edificios, de urbanización o reurbanización, de la creación de dotaciones y equipamientos, y de mejora de la accesibilidad de sus espacios públicos" ${ }^{26}$, con este criterio se ha procedido en zonas especialmente castigadas por el envejecimiento, dotándolas de servicios o equipamientos necesarios pero inexistentes hasta ese momento.

\subsection{Renovación urbana}

Como hemos señalado, la mayor parte de los ancianos vive en sus casas, su entorno vital es el barrio, por ello las administraciones han impulsado nuevos planes integrales, algunos muy ambiciosos como el del Casco Histórico (P.I.C.H.) ${ }^{27}$, en zonas con altas tasas de población mayor, que suponen actuaciones tanto de renovación como de rehabilitación. Se pone en marcha a partir del año 1997, con base al P.G.O.U.Z ${ }^{28}$ de 1986, intentando un plan integral de modernización urbana y social, con lo que sus actuaciones abarcan aspectos tanto de renovación (nuevos edificios de las calles San Pablo, de Las Armas, Predicadores) como de integración y revitalización social de un barrio muy degradado. Ha te-

(24) Datos obtenidos del Servicio Aragonés de Salud. 2010.

(25) Datos del IASS para 2010.

(26) GOBIERNO DE ARAGÓN. Decreto 60/2009, de 14 abril del Gobierno de Aragón, por el que se regula el Plan aragonés para facilitar el acceso a la vivienda y fomentar la rehabilitación 2009-2012.

(27) Plan Integral del Casco Histórico.

(28) Plan General de Ordenación Urbana de Zaragoza. 


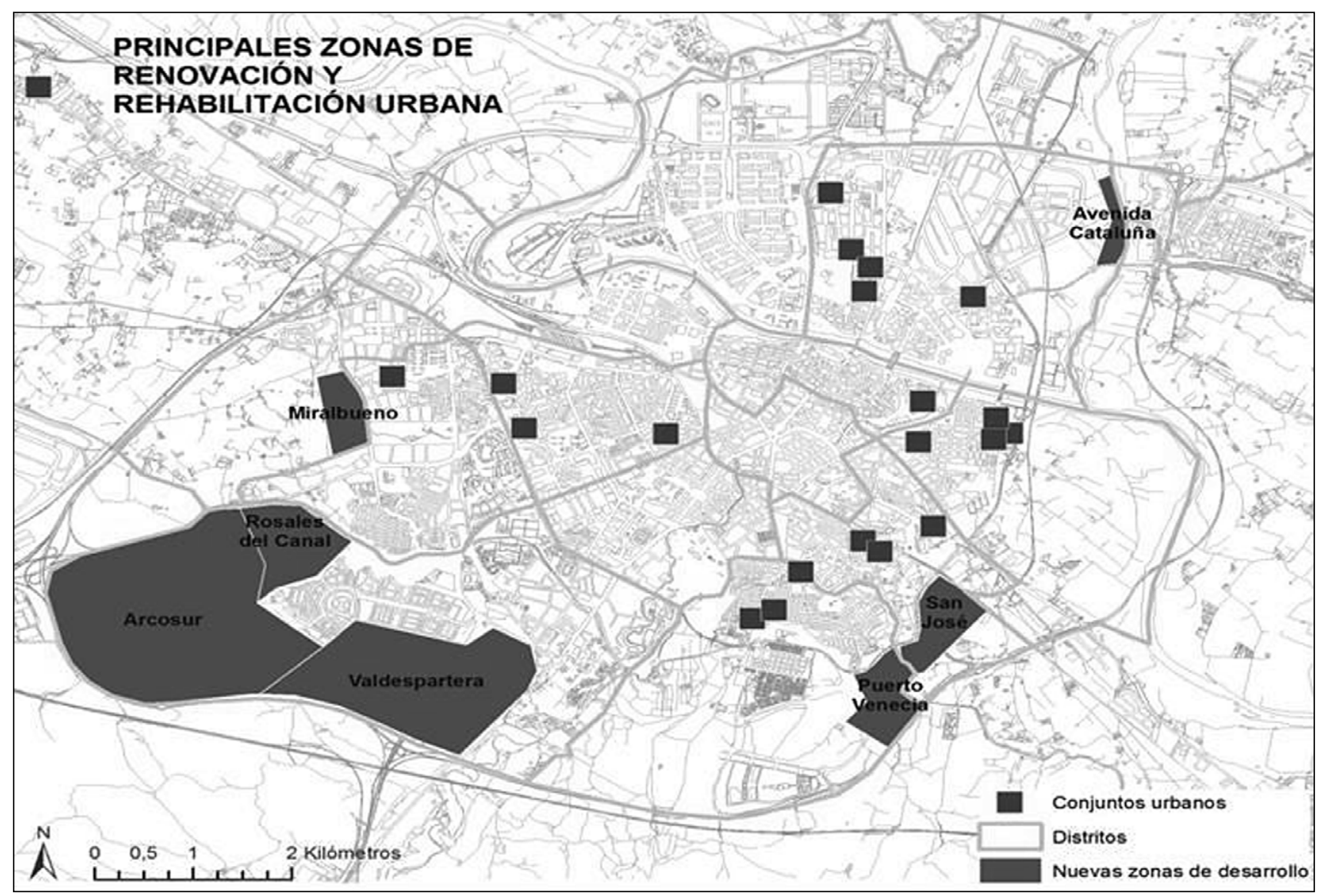

$\Delta$ Figura 4. Zonas de renovación y rehabilitación recientes.

nido una continuidad en el tiempo, en base a los P.O.G.U.Z de 2002 y 2007, con el derribo de edificios y sustitución por pequeños parques a través del programa "Estonoesunsolar" (sic.) en los barrios de San Pablo y La Magdalena (Casco Histórico). A partir de 2001 el ámbito de aplicación del P.I.C.H. se extendió a toda la ciudad y sobre edificios de más de 40 años, zonas como El Picarral y Vadorrey (El Rabal). Actualmente, y bajo el marco normativo del P.G.O.U.Z. de 2007, se han acometido también actuaciones de renovación en los barrios de La Jota y avenida de Cataluña (El Rabal); la última gran actuación de renovación, fue la que supuso la Expo 2008, aunque afectó más a los viales y conectividad.

\subsection{Rehabilitación urbana}

Otro de los aspectos donde el envejecimiento ha influido de forma decisiva es la rehabilitación de edificios, sobre todo en lo que a accesibilidad se refiere, como las inversiones en dotaciones de medios de elevación de núcleos residenciales antiguos carentes de estos elementos, han sido cuantiosas, así las administraciones, a través de Zaragoza Vivienda ha desarrollando políticas de rehabi- litación urbana, en base a los P.G.O.U.Z de 1989, 2002 y 2007, que en un inicio afectaron al Casco Histórico y que, desde el año 2001, se han extendido al resto de la ciudad mediante la aplicación de la Ordenanza Municipal de Fomento a la Rehabilitación Privada. Paralelamente se ha generado un programa especifico de ayudas para las zonas que lo precisaban con mayor urgencia, denominadas zonas ARI ${ }^{29}$, y que se gestionan, también, a través de la Sociedad Municipal Zaragoza Vivienda. Estas actuaciones suponen rehabilitaciones integrales en barrios y centros degradados o con edificios afectados por problemas estructurales, con núcleos de concentración de infravivienda y chabolismo, (Oliver, Las Fuentes, El Rabal, Delicias, San José) así como obras de mejora de la habitabilidad, seguridad, accesibilidad y eficiencia energética.

\section{VALORACIÓN Y CONCLUSIONES}

El fenómeno del envejecimiento demográfico es un hecho de gran trascendencia social cuyas consecuencias se evidencian en un amplio espectro de sectores y que, a la luz

$\left.{ }^{29}\right)$ Áreas de Rehabilitación Integral. 
de los datos, se acentuarán en los próximos años. A pesar de que la población en Zaragoza todavía sigue creciendo, se asiste a un cambio profundo en su estructura por edades, manifestándose en el incremento del colectivo del grupo de personas mayores y en la disminución de los de menor edad. Su pirámide de población presenta una forma romboidal, propia de poblaciones envejecidas, el estrechamiento de la base refleja la gran caída de la tasa de natalidad, que se ha producido durante los últimos veinte años. El menor número de personas que se incorporan a esta cohorte, junto con la elevada esperanza de vida (83,4 años en las mujeres y 76,8 en los hombres) producirá, en la composición del grupo de mayores, un sobreenvejecimiento significativamente mayor que el actual. Por distritos, Centro, Delicias y Las Fuentes superan el 20\% de población mayor de 64 años, casi un $25 \%$ en el distrito Centro. En algunos de ellos se aprecia un rejuvenecimiento, caso de Casablanca, fomentado por la construcción de nuevos barrios con altos porcentajes de VPO (Valdespartera, Arcosur). Las estructuras más jóvenes se asientan en el sur (Miralbueno, Casablanca), y norte (Actur, Santa Isabel y Barrios Rurales Norte), producto de la llegada de población extranjera y de la redistribución de los contingentes jóvenes del resto de los distritos, atraídos por el menor precio de la vivienda; debido a ésto algunos han perdido población, incrementándose porcentualmente el grupo de población vieja, caso de Centro o Delicias. Esta estructura demográfica, además de su repercusión en el aumento del gasto social, tiene su manifestación en el paisaje urbano pues condiciona de manera directa la creación, situación y modificación de infraestructuras específicas y la actuación directa sobre el espacio, en forma de rehabilitación de edificios, trazado de vías, adecuación del entorno, etc.

Atendiendo a la gravedad del problema podemos dividir la ciudad en tres zonas caracterizadas por sus porcentajes de población mayor. En un primer lugar los más envejecidos son principalmente los distritos de posición central y más antiguos, Casco Antiguo, Centro, Universidad, también se incluyen aquí otros limitrofes como Las Fuentes, La Almozara o San José. Mantienen tasas de envejecimiento que superan el 20\% y de sobreenvejecimiento por encima del 5\%; su población ha descendido en los últimos años entre un 1\% y $2 \%$; existe además un basculamiento de la sex ratio hacia el sexo femenino que se agudiza radicalmente en la cúspide de sus pirámides.

Un segundo grupo se localizaría en una posición periférica extrema y con grados de envejecimiento de entre el 16\%-20\%, son los barrios Rurales Norte, Oeste y Torrero-La Paz. Aquí los parámetros se dulcifican gradualmente, pero presentando empero tendencia a la regresión, con una base estrecha y un incremento todavía significativo de la feminidad a partir de los 64 años; han crecido demográficamente en tres años con unas tasas moderadas, en torno a un $1 \%$ para todo el periodo.
En último lugar, los más dinámicos y con menores niveles de población envejecida, se ubicarían en la periferia del núcleo urbano, con volúmenes menores del 16\%, hasta el $8 \%$ en los casos más afortunados (Casablanca, Miralbueno). Se incluyen en este grupo los de la margen izquierda (Actur, El Rabal, Santa Isabel), Oliver-Valdefierro y los dos citados, corresponden a zonas de atracción de contingentes jóvenes y han crecido en torno a un 5\% en el trienio.

Esta dinámica demográfica y su correspondiente distribución geográfica han propiciado consecuencias de desigual calado entre los distritos y que, sin lugar a dudas, tienen su reflejo en el paisaje urbano. Entre los efectos debemos de señalar la falta de reemplazo poblacional, muy acusada entre los componentes del primer grupo, el sobreenvejecimiento, galopante de éstos últimos, y el desequilibrio de la estructura por sexos, con un peso cada vez mayor de las mujeres.

En la estructura de los hogares los datos muestran la tendencia al incremento de ancianos que viven solos (más del 14\% en distritos del grupo 1 como Casco Antiguo y Centro) y a la disminución de su número de miembros por hogar (los más envejecidos arrojan un promedio de 2,5 personas por hogar, cuando la media en Aragón está en 2,9) lo que obligará a reforzar significativamente los servicios de atención domiciliaria y la consiguiente inversión pública. El presupuesto en equipamientos va a estar condicionado por esta evolución actual y su tendencia a corto plazo, sin embargo los cambios de estructura demográfica son más rápidos en algunas zonas (Centro ha incrementado celéricamente su población vieja desde hace 10 años, mientras que Casco Antiguo, aún en niveles elevados, la ha visto descender), lo que da como resultado una desigualdad entre la oferta de servicios o equipamientos y las necesidades puntuales. En este sentido se observa, además, una mayor agilidad de respuesta entre la oferta privada, asi el número de plazas geriátricas es considerablemente mayor en el sector privado, el 80\% del total, no obstante en su distribución influyen los criterios economicistas de gasto, localizando sus instalaciones en zonas donde el suelo es más barato, independientemente de la demanda del servicio, caso de Barrios Rurales que concentra el 20\% de todas las plazas, mientras que Las Fuentes dispone del 1,5\% o Centro del 8,1\%, con un porcentaje de mayores de 64 años y población dependiente mucho mayor. En cuanto a la atención sanitaria la tendencia se invierte, el 75\% de las camas hospitalarias son públicas; al igual que en la especialización geriátrica estos servicios están lejos de cubrir la demanda ya que se ha primado el modelo del gran hospital de referencia, de carácter general y localizado, lo que obliga a frecuentes desplazamientos. En los centros de salud, existe mayor flexibilidad respecto a su implementación pero tampoco su distribución responde con la suficiente celeridad a los cambios de estructura demográfica, así Delicias dispone de 4 centros de salud para una población de unos 100.000 habitantes, de la que el 21,37\% tiene más de 64 años; Actur con 60.000, una 
tasa del $10 \%$ de mayores y menor extensión, también posee el mismo número, Las Fuentes, con una población similar y más envejecida sólo cuenta con 2. Lo mismo podemos decir del desequilibrio entre médico de familia/cartilla sanitaria; la media en Aragón es de 1.187 cartillas por facultativo, Zaragoza presenta ratios de entre 1.500-2.000, lo que nos indica que la atención médica está, no solo infradotada sino también mal distribuida, pues los distritos envejecidos manifiestan ratios altas, más cartillas por médico, polarizándose este desajuste en los anteriormente señalados del grupo 1(Casco Viejo, Centro, Las Fuentes).

Consecuencia directa del envejecimiento es, también, el aumento del nivel de población dependiente, en este sentido los incrementos de las tasas de dependencia son más acusados en los distritos envejecidos, que corresponden con el área sanitaria Zaragoza I (Casco Viejo, Centro, Universidad, la Almozara y Las Fuentes), encontrándonos con un $7 \%$ de población dependiente, frente al 4,6\% de media en Zaragoza. Esto obliga a mayores esfuerzos de inversión en equipamiento y en nuevos servicios, que ha forzado a desarrollar iniciativas novedosas como la ayuda a domicilio, la teleasistencia y el apoyo al cuidador, de gran demanda en estas últimas zonas.
El incremento de esta población envejecida ha condicionado también la estructura del transporte público, principalmente del autobús y de los nuevos metro y cercanías, ha influido en la dirección de los flujos, en los nuevos trazados de sus líneas, reforzando los que conducen a destinos de mayor demanda, centros hospitalarios, así como creando servicios especializados cuales son los autobuses P.M.R.S (personas de movilidad reducida severa).

Todo lo señalado hasta ahora se ha plasmado en el paisaje urbano, modificando su morfología, pero, sin duda, su mayor efecto lo han producido las actuaciones y renovaciones urbanas, que se han llevado a cabo sobre todo en zonas con mayor envejecimiento, en unos casos con actuaciones de acceso (instalación de ascensores en edificios antiguos) que han acabado afectando a amplias zonas de la ciudad como Las Fuentes, Casco Viejo y barrios de El Rabal. En otros casos con resultados de mayor calado, creación de nuevos espacios, reorganización profunda de conjuntos urbanos (nuevos parques, viales, accesibilidad, y equipamiento para mayores) como el Plan Integral del Casco Viejo (P.I.C.H.) de objetivos más ambiciosos, orientados a la modernización paisajística y social del barrio, y que han terminado por expandirse hacia el resto de las áreas urbanas.

\section{BIBLIOGRAFÍA}

Aubá Estremera, N. Et All: "El envejecimiento de la población de Aragón (1900-1981)", Geographicalia, n. ${ }^{\circ} 25,1985$, pp. 5-44.

AYUNTAMIENTO DE ZARAGOZA Y ZARAG0ZA GLOBAL: Atlas de la ciudad. Zaragoza 2009. Zaragoza, Ayuntamiento de Zaragoza y Zaragoza Global, 2009. P. 20. http://www.zaragoza.es/contenidos/ Atlas_Zaragoza_2009/Atlas_A.pdf

Borobio Enciso, M. P.: El barrio de las Delicias de Zaragoza. Zaragoza, Institución Fernando el Católico, 1980.

Calvo Palacios, J. L.: "Unidades de análisis y densidades urbanas: Zaragoza", Geographicalia, n. ${ }^{\circ}$, 1980, pp. 5-32.

Ebropolis: Plan estratégico de Zaragoza, revisión de junio de 2006. Zaragoza, Ebrópolis, 2006. http://www.ebropolis.es/files/File/Plan\%20 Estratgico/PLAN\%20ESTRAT\%C3\%89GIC0.pdf

- Sistema de Indicadores de Seguimiento del Plan Estratégico de Zaragoza y su entorno. Informe 2010. Zaragoza, Ebrópolis, 2011. http:// www.ebropolis.es/files/File/Plan\%20Estratgico/Informelndicadores10-ebropolis.pdf

Escolano Utrilla, S.: "Densidad de población y sustentabilidad de la ciudad de Zaragoza" en LONGARES, L. A y PEÑA, J. L. Aportaciones geográficas en memoria del Profesor L. M. Yetano. Zaragoza, Universidad de Zaragoza, 2002, pp. 173-182.

Gobierno de Aragón: "Estado de salud de la población aragonesa, sus determinantes y las actuaciones del departamento de salud y con- sumo, 2010". Zaragoza, Gobierno de Aragón, p.12. http://www. aragon.es/estaticos/GobiernoAragon/Temas/Familias/Documentos/ EstadoSaludPoblacionAragon_sintesis.pdf

Instituto ARAgonés de Estadistica. Indicadores demográficos del Movimiento Natural de la Población Distritos censales del municipio de Zaragoza. Años 1996-2000. Zaragoza, IAEST, 2003.

LANASPA, L., PUeYO, F. y SAnZ, F.: Factores de localización y tendencias de población en los municipios aragoneses. Zaragoza, FUNDEAR, Documentos de Trabajo n. ${ }^{\circ}$ 6, 2004.

OCAÑA OCAÑA, C.: "Microanálisis sociodemográfico de espacios urbanos", Boletín de la A.G.E., n. ${ }^{\circ} 40,2005$, pp. 5-34.

Plumed Gómez, A.: Zaragoza horizonte 2008: hacia la consolidación de proyectos urbanísticos a gran escala y propuesta de conectividad en transporte público. (Tesina s.p.) Universidad Politécnica de Cataluña, Barcelona, 2005.

Rubio Gracia, J. L.: "El Barrio de la Química: contribución al estudio de la geografía urbana de Zaragoza", Geographicalia, n. ${ }^{\circ} 2,1978$, pp. 21-63.

Servicio de Planificación y Ordenación de Servicios Sociales: Plan Estratégico de Servicios Sociales de Aragón 2012-2015. Diagnóstico de situación (Borrador). Zaragoza, Gobierno de Aragón, 2011, pp. 60-75.

W. AA.: Diagnosis de la red actual de transporte urbano de Zaragoza y propuestas de mejora. Zaragoza, Fundación Ecología y Desarrollo, 2011, p. 39. 